\title{
Explicitly-Coupled Cloud Physics and Radiation Parameterizations and Subsequent Evaluation in WRF High-Resolution Convective Forecasts
}

\author{
Gregory Thompson ${ }^{1}$, Mukul Tewari ${ }^{1}$, Kyoko Ikeda ${ }^{1}$, Sarah Tessendorf ${ }^{1}$, \\ Courtney Weeks ${ }^{1}$, Jason Otkin ${ }^{2}$, and Fanyou Kong ${ }^{3}$ \\ ${ }^{I}$ Research Applications Laboratory \\ National Center for Atmospheric Research \\ Boulder, CO, USA \\ ${ }^{2}$ Cooperative Institute for Meteorological Satellite Studies \\ University of Wisconsin-Madison \\ Madison, WI, USA \\ ${ }^{3}$ Center for Analysis and Prediction of Storms \\ University of Oklahoma, \\ Norman, Oklahoma, USA
}

Submitted to Atmospheric Research

07 September 2015 


\begin{abstract}
The impacts of various assumptions of cloud properties represented within a numerical weather prediction model's radiation scheme are demonstrated. In one approach, the model assumed the radiative effective radii of cloud water, cloud ice, and snow were represented by values assigned a priori, whereas a second, "coupled" approach utilized known cloud particle assumptions in the microphysics scheme that evolved during the simulations to diagnose the radii explicitly. This led to differences in simulated infrared (IR) brightness temperatures, radiative fluxes through clouds, and resulting surface temperatures that ultimately affect model-predicted diurnally-driven convection. The combined approach of evaluating simulated versus observed IR brightness temperatures, radiation reaching the ground, and surface temperature forecasts revealed the root model biases better than evaluating any single variable. This study found that the Weather Research and Forecasting (WRF) model predicted less overall clouds than was observed, particularly in the mid- troposphere, but that properly connecting the assumptions of particle sizes in the microphysics scheme to the radiation scheme resulted in sensible cloud-radiation indirect effects and modest improvements in simulated IR brightness temperature, amount of solar radiation reaching the ground, and surface temperature.
\end{abstract}




\section{Introduction}

Radiation and cloud microphysics parameterizations are perhaps the most computationally demanding part of numerical weather prediction models. In the last few decades, a plethora of new schemes of each type has emerged with increasingly complex treatment (e.g., Stensrud, 2007) since computational power has greatly increased. Specialists in microphysics modeling have increased number of predicted species from only a single cloud water and ice species (i.e., mass mixing ratios) to more complex double-moment schemes with number concentration and/or additional ice species (Meyers et al, 1997; Morrison and Pinto, 2005; Milbrandt and Yau, 2005; Woods et al, 2007; Thompson et al, 2008; Morrison and Milbrandt, 2015). Simultaneously, radiative transfer modeling experts have introduced more complex band-by-band (wavelength) treatments (Mlawer et al, 1997) while accounting for more gaseous and aerosol species (ozone, $\mathrm{CO}_{2}$, water vapor, dust, black carbon, sulfates, etc.). Even with more recent advances in radiation schemes, numerous studies indicate wide-ranging differences in clear-sky radiation (Fouquart et al, 1990; Boucher et al, 1998; Zamora et al, 2005) due to internal methods or complexity or species considered. Far greater uncertainties arise with treatments of clouds by various radiation schemes. Furthermore, as code creators of these seemingly separate parameterizations focus their specialization even further, the end result is often a disconnect between assumptions of water droplet size and ice crystal size and/or shape between the set of these two schemes (Stensrud, 2007).

In general, global climate models (GCMs) do not suffer from this gap of knowledge between the microphysics and radiation schemes, primarily because they were built with this requirement in mind for climate simulations/applications; however, the same situation is less common in mesoscale models such as the Weather Research and Forecasting (WRF) model (Skamarock and Klemp, 2008). The reason is primarily the incorporation of many choices of physical parameterizations that can be inter-connected with the fewest shared variables thus giving the most flexibility. The inclusion of properly computed radiative effective size of cloud water droplets is paramount when discussing climate impacts associated with aerosol indirect effects. Furthermore, the IPCC reports clearly reveal that the largest uncertainty in all climate model simulations continues to be the aerosol indirect effects. The various IPCC climate models account for the physical principle that a cloud populated with a large number of small droplets has a higher shortwave reflectance (albedo) than the same liquid water content cloud composed of fewer but larger droplets (Twomey, 1979). While this principle is widely known and accounted for in various radiation parameterizations, the explicit connection between a cloud microphysics parameterization and its radiative effective size of water and ice species used by the radiation parameterization isn't assured in all models. As more and more non-GCMs (i.e., WRF) are increasingly used in regional climate modeling applications, an effort to connect assumptions made by different code authors of separate physical parameterizations will be required for proper application to climate-scale problems.

Visible and infrared satellite images together with example WRF- model forecasts of shortwave radiation reaching the ground near mid- day are shown in Fig. 1 and illustrate how WRF's implementation of the Geophysical Fluid Dynamics Laboratory (GFDL) radiation scheme treats clouds ${ }^{1}$ as compared to the Rapid Radiative Transfer Model-Global (RRTMG) scheme. Note the extensive areas of reduced radiation reaching the surface in RRTMG as compared to GFDL. This occurred because the current implementation of the GFDL scheme in WRF includes only the cloud water and cloud ice variables while ignoring the snow variable when calculating radiative fluxes, whereas the current implementation of the RRTMG scheme includes snow in addition to these two variables. Meanwhile, in the model and in reality, it was

${ }^{1 *}$ The operational Hurricane WRF (HWRF) model uses GFDL radiation with a different microphysics scheme in which the disparity for ice/snow clouds shown in Fig. 1 does not reveal this problem. 
snowing heavily at the time shown in Fig. 1 in Missouri and other nearby areas in both simulations containing equally deep and thick ice-phase clouds. This finding motivated us to explore the connections between these two radiation schemes (as implemented in the WRF model) and all hydrometeor species (cloud water, cloud ice, rain, snow, and graupel). Furthermore, we explored the various particle and size distribution assumptions that the microphysics scheme inherently uses and could communicate directly to the radiation scheme.

Prior work has evaluated the accuracy of simulated cloud fields in research and operational NWP models through comparisons of real and model-derived synthetic satellite observations (Karlsson 1996; Rikus 1997; Tselioudis and Jakob 2002; Lopez et al. 2003; Sun and Rikus 2004; Otkin et al. 2009). The model-to-satellite approach has been used to validate and improve the accuracy of cloud microphysics schemes (Grasso et al. 2014; Grasso and Greenwald 2004; Chaboureau and Pinty 2006; Otkin and Greenwald 2008; Grasso et al. 2010; Jankov et al. 2011). Synthetic satellite radiances derived from highresolution NWP models have also been used as a proxy for future satellite sensors (Otkin et al. 2007; Grasso et al. 2008; Feltz et al. 2009) and have been shown to be a valuable forecast tool at convective scales (Bikos et al. 2012). Another example of the usage of the model-to-satellite approach is found in Cintineo et al (2014) who showed a distinct lack of sufficient clouds with cloud-top temperature centered at about $\mathrm{T}=260 \mathrm{~K}$ regardless of using four different microphysics schemes. This suggests the possibility that the model error is not related to cloud microphysics but rather other model errors. Another motivation of our research was to determine if assumptions with the radiation scheme or the proper coupling of effective size by the microphysics scheme together with the radiation scheme might be a possible cause of the reported error.

This paper is organized as follows: a description of the numerical experiments is found in the next section along with more detailed descriptions of the radiation scheme used and how specific alterations were implemented. Next, the results of ensemble experiments are presented in Section 3 highlighting the differences between coupled versus uncoupled cloud physics variables and radiation. Section 4 provides a more detailed inspection of example cloud areas to illustrate small-scale effects that are less obvious in the overall statistics. The final section contains a summary and conclusions.

\section{Methodology}

\section{Numerical experiments}

The simulations used in this study were performed with the Weather Research and Forecasting (WRF) model, version 3.4.1 with modifications discussed below. The WRF model includes many options to parameterize radiation, planetary boundary layer (PBL), microphysics, and land-surface processes and interactions. The University of Oklahoma's Center for Analysis and Prediction of Storms, OU-CAPS, has performed WRF-model ensembles for a number of recent years during six weeks in late Spring (e.g., Kong et al. 2014; Xue et al. 2010; Clark et al. 2012; 2015). In these simulations, the model was configured with 3 or $4 \mathrm{~km}$ horizontal grid spacing depending on which year and 51 vertical levels for a domain encompassing most of the continental U.S. To increase ensemble spread and to evaluate sensitivities due to physical parameterizations, each of the various members incorporated different PBL, radiation, and microphysics schemes, as well as different initial and lateral boundary data, and other variants. For the results discussed in this study, the ensemble members evaluated came from the 2013 Experimental Forecast Project, and all used the same PBL scheme referred to as Mellor-Yamada-Janic (Mellor and Yamada 1982, Janjic 2002), the Noah land-surface model (Chen and Dudhia 2001), the Thompson et al. (2008) bulk microphysics scheme and Rapid Radiative Transfer Model (RRTMG; Iacono et al. 2000) radiation scheme.

OU-CAPS ran WRF once daily from 23 Apr to 07 Jun 2013 starting each day at 0000 UTC and simulating for 48 hours, except over most weekends using the domain shown in Fig. 2. The initialization 
process included radar data assimilation to produce initial clouds, however, the results reported herein exclude the first six hours of forecast to avoid most issues related to model spin-up. Of the total 36 days with WRF model runs, all except two with corrupted model output files were used in subsequent analysis presented herein.

For the results shown later, the outer-most ring of 50 model points was ignored such that lateral boundary condition influences on the hydrometeors (cloud water, cloud ice, snow, rain, and graupel) would not profoundly influence the analyses. Under certain flow regimes and wind speed, eliminating only 50 points may be too few, but visual inspection of numerous model fields including individual hydrometeor species and synthetic satellite imagery deemed this number sufficient.

\section{Radiation parameterization interface changes}

The RRTMG scheme performs the radiative forward model calculations given clear or cloudy sky conditions as well as an option to treat aerosols, although this latter element was not enabled in these experiments. The existing WRF interface to RRTMG neglects partial cloudiness as nearly every grid box is considered completely cloudy if the microphysics parameterization contains explicit cloud hydrometeors or is considered entirely cloud-free if no such hydrometeors are predicted. RRTMG uses look-up tables to compute the absorbed, emitted, reflected, and transmitted components of broadband solar and longwave radiation within specific intervals (bins) of wavelength. The indexes of its internal look-up tables are wavelength and radiative effective radius of water droplets or ice crystals and resultant values of asymmetry parameter, single-scattering albedo, and cloud optical depth are used to compute radiative fluxes. Within the scheme the tables assume that water droplet radius ranges from 2.5 to $60.0 \mu \mathrm{m}$ (Hu and Stamnes, 1993) and a population of randomly-oriented hexagonal ice crystals with radius between 2.0 and $140.0 \mu \mathrm{m}$ (Fu et al, 1998). The interface code used between the WRF model and RRTMG strictly constrains the input sizes of water drops or ice crystals to these bounds.

The original RRTMG implementation into WRF used pre-determined values of cloud water and ice crystal size by default. While the version of the RRTMG scheme that gets activated when running the WRF-Chemistry model (Grell et al. 2005) contains direct calculations of water droplet sizes, although not ice size, the regular WRF code does not couple the droplet or crystal sizes with the particle size assumptions made by the grid-resolved microphysics scheme. The original v3.4.1 WRF implementation of the interface code for RRTMG assumes that cloud water droplets vary between 8 and $14 \mu \mathrm{m}$ dependent upon temperature over land points and by modified relations over snow, sea ice, or open ocean. Similarly, the assumed ice crystal size in the WRF interface code is purely temperature dependent with values shown by Fig. 3. So, while a few microphysics schemes have mono disperse assumption of cloud water droplet spectra, some others have generalized gamma or inverse exponential assumption. As an example, the cloud droplet size distribution assumed in the Thompson et al. (2008) scheme has a variable gamma shape distribution that shifts according to the assumed droplet number concentration. Therefore the standard WRF code was modified in order to pass explicitly-computed radiative effective radii of cloud water, cloud ice, and snow from the Thompson et al. (2008) microphysics scheme into the RRTMG scheme. The updated code is now available in versions numbered v3.5.1 or higher when using only the combination of Thompson et al. (2008) or Thompson and Eidhammer (2014) microphysics options together with RRTMG shortwave and longwave radiation schemes. At the time of this writing, no other combinations for microphysics and radiation options contain proper physical coupling in a non-WRF-Chemistry version of the model. The cloud droplet, cloud ice, and snow radii are directly computed using the fundamental droplet and ice/snow parameters specific to the microphysics scheme. Using each species own number distribution and mass-diameter assumptions, a fully consistent effective radii is computed in the microphysics body of code and subsequently passed to the RRTMG interface code. Since the usual size of rain drops and graupel particles is far larger and the number density far lower than the other three species, 
rain and graupel were neglected in the radiation treatment as is currently done within all WRF radiation schemes at this time.

The radiative effective diameter $\left(D_{e}\right)$ of water drops is the ratio of third $\left(\mathcal{M}_{3}\right)$ to second $\left(\mathcal{M}_{2}\right)$ moments of the drop size distribution (Slingo, 1989) as shown in Eq. (1) below:

$$
\overline{D_{e}}=\frac{\mathscr{M}_{3}}{\mathcal{M}_{2}}=\frac{\int_{0}^{\infty} D^{3} N(D) d D}{\int_{0}^{\infty} D^{2} N(D) d D}
$$

where $D$ is diameter, $N(D)=N_{0} D^{\mu} \mathrm{e}^{-\lambda D}$ is the assumed size distribution, $\mu$ is the gamma shape factor and $\lambda$ is the slope, which after integrating over the entire size distribution produces the final radiative effective radius $\left(r_{e}\right)$ given by Eq. (2).

$$
\overline{r_{e}}=\frac{1}{2} \times \frac{(3+\mu)}{\lambda}
$$

The cloud water gamma distribution shape parameter, $\mu$, varies as a function of droplet number concentration, which is fixed constant in Thompson et al. (2008) but not constant in the "aerosol-aware" Thompson and Eidhammer (2014) scheme. As such, changes to number concentration with constant liquid water content properly lead to changes in mean effective radii, something that is otherwise not available in a non-WRF-Chemistry framework. Similar to cloud water droplets, the cloud ice variable also follows a generalized gamma distribution but with $\mu=0$, which effectively creates an inverse exponential distribution for cloud ice.

In order to compute a radiative effective radius of snow, all characteristics of the assumed snow number density function and size-to-mass relation must be used. Since the Thompson et al. (2008) scheme implements the Field et al. (2005) number distribution function, shown below in Eq. (3),

$$
N(D)=\frac{\mathscr{M}_{2}^{4}}{\mathscr{M}_{3}^{3}}\left[\kappa_{0} e^{-\frac{\mathscr{M}_{2}}{\mathscr{M}_{3}} \Lambda_{0} D}+\kappa_{1}\left(\frac{\mathscr{M}_{2}}{\mathscr{M}_{3}} D\right)^{\mu_{s}} e^{-\frac{\mathscr{M}_{2}}{\mathscr{M}_{3}} \Lambda_{1} D}\right]
$$

and the Cox (1988) mass-diameter power law $\left[m(D)=0.069 D^{2}\right]$, the calculation of effective radius of snow is profoundly different than one might get if spherical and constant density snow combined with an exponential distribution was assumed. To illustrate how different these values can be, a sample snow size distribution found at $\mathrm{T}=-20^{\circ} \mathrm{C}$ and snow content of $0.2 \mathrm{~g} \mathrm{~m}^{-3}$ produces a radiative effective radius of $336 \mu \mathrm{m}$ when using all the proper characteristics of the microphysics scheme. If constant density $\left(100 \mathrm{~kg} \mathrm{~m}^{-3}\right)$, spherical snow and an inverse exponential distribution is used together with a $\mathrm{Y}$ - intercept parameter of $2 \times 10^{7} \mathrm{~m}^{-4}$, taken from Houze et al. (1979), then the calculated radius would be $634 \mu \mathrm{m}$. However, if the standard WRF interface code for ice radius was applied, then the value would be approximately $100 \mu \mathrm{m}$ (referring to Fig. 3). This is illustrated in Fig. 4 showing the distribution represented by Eq. (3) using values previously mentioned as well as the inverse exponential distribution.

Unfortunately, in the initial implementation of the calculations of snow size, a mistake was made in which the snow size was incorrectly diagnosed by accidentally setting $\Lambda_{1}$ to zero, thereby only considering the first term on the right-hand side of Eq. (3), which means that radiative effective radius of snow originally used the part of the snow size spectrum shaded in gray in Fig. 4. The incorrect snow size code was run by OU-CAPS for the duration of the 2013 Spring Experiment, and the error was not discovered until later that summer. Once corrected, OU- CAPS produced a new set of simulations using the corrected code for the simulations of 08 and 18 May. It was simply too costly to re- run a larger number of simulations with the newly corrected code. The nomenclature in the results and remaining sections will refer to the "control" or "uncoupled" WRF ensemble member for the original WRF v3.4.1 code that did not 
couple the cloud water, cloud ice and snow size to the RRTMG radiation code. The WRF ensemble member with coupled but incorrect snow size is referred to as " $\mathrm{m} 25$ " while the corrected snow size was used in the ensemble member called " $\mathrm{m} 30$ " for two days only. These two days were picked at random and were representative of most days with broad cloud areas in synoptic regime flow in the north parts of the domain and mesoscale convection in the south.

\section{Observed satellite data}

Observed GOES- 13 satellite data were collected between 23 Apr and 22 May 2013 but had to be switched to GOES- 15 from 23 May to 06 Jun due to a total outage of GOES- 13 from 23 May onward. In the results section below, some comparisons will be made for times and locations considered to be cloudy versus either cloudy or clear, so the observed satellite data was post-processed into a simple cloud mask. The cloud mask was created first using the normalized GOES visible albedo (channel 1, $0.67 \mu \mathrm{m}$ ) exceeding $25 \%$ combined with solar zenith angle exceeding 0.2 radian (daytime). Since this will also capture highly reflective desert surfaces, the data were subsequently screened for pixels whose difference from a climatology of satellite albedo differed by more than $10 \%$. For example, bright pixels in the southwest desert areas of the U.S. had to have an albedo exceeding $10 \%$ of their climatological value in order to be classified as cloudy. The first albedo screening would also result in some clear-sky, snowcovered ground pixels being misidentified as cloudy. Therefore, these pixels were screened using the multi-spectral infrared data using channel $2(3.9 \mu \mathrm{m})$ and channel $4(10.8 \mu \mathrm{m})$ after scaling radiances into brightness temperatures, BT2 and BT4 respectively. Prior diagnosed cloudy pixels were changed to clearsky snow cover if - $20<\mathrm{BT} 4<0 \mathrm{C}$ and (BT2-BT4) $<2$. Although fairly simplistic overall, this cloud mask worked effectively due to the time of year (May-June) and the scene of view since most snow-covered ground was confined only to mountainous regions. Such a simplistic method would not work to identify clouds year-round or worldwide.

\section{Synthetic (WRF) satellite data}

Simulated GOES channel 4 IR brightness temperatures were generated hourly $(0-48 \mathrm{~h})$ from all WRF model output using the Successive Order of Interaction (SOI) forward radiative transfer model (Heidinger et al. 2006; O'Dell et al. 2006) code provided by the University of Wisconsin group, who also used the same program in a similar way to compare model to observations in Cintineo et al. (2014). The only change from their prior usage was a more accurate calculation of radiative effective diameter of cloud droplets, cloud ice, and snow consistent with the Thompson et al. (2008) microphysics scheme using the same equations presented earlier. The software to create synthetic satellite images from WRF output generated other GOES IR channels, however, for the results section below, only the channel 4 results indicative of cloud-top temperature were used.

\section{Shortwave radiation measurements}

Observations of shortwave radiation reaching the ground were retrieved from 116 U.S. Climate Reference Network (USCRN; Diamond et al 2013) sites and 15 Ameriflux sites around the continental U.S. for the time period of interest. In the results section below, when comparing the WRF data to these measurements during daytime periods only, we screened the measurements for times when the satellitedetermined solar zenith angle exceeded 0.2 radian. In addition, for comparing times during which clouds existed, the USCRN data were screened by the simplistic GOES satellite mask mentioned above.

\section{Surface temperature observations}

Hourly measurements of surface temperature at 2500 to 3000 airports in the domain shown in Fig. 2

were collected from the National Weather Service METAR-format observations. In addition, 
approximately 75 USRCRN sites included temperature data, however, we found that these data essentially added nothing new to the results found below due to the density of METAR data across the U.S. Similar to the radiation measurements, we screened the temperature data points to locations with clouds found in the simple GOES cloud mask as well as any WRF model points that had clouds. Since the overall aim of this research is to isolate the impact of modeled cloud-radiation coupling, any clear sky temperature bias in the model was not the focus of this study.

\section{Results}

One of the major difficulties in analyzing these ensemble model sensitivities is that the magnitude of the error/bias of any individual member as compared to observations greatly exceeds the change in error by introducing the radiation coupling. While this might imply that the coupling is relatively unimportant, we plan to show specific cloud regimes in which positive impacts to incoming surface radiation and temperature forecasts results from this addition (Section 4). Since the focus of this study investigates cloud and radiation coupling, we concentrated our analysis on locations in both the observations and the model in which we diagnosed the existence of clouds in all of the products. Due to the model initialization time of 0000 UTC, which is near sunset time in the U.S., and due to model spin-up time, we neglected the first 6 hours of each forecast.

\section{Satellite comparison}

An example of the observed and synthetic satellite data near 1800 UTC 08 May 2013 is shown in Fig. 5. Clockwise from top-left is the GOES- 13 observed IR brightness temperatures, followed by the control, $\mathrm{m} 25$, and $\mathrm{m} 30$ experiments, respectively. Overall the correspondence is relatively good with five primary features present: 1) a well-developed low-pressure system over the northeast U.S., 2) a mix of shallow/warm and mid-troposphere clouds extending from north to south through the central U.S., 3) scattered, moderately cold clouds extending from CO to OR likely along a frontal boundary, 4) a combination of high-altitude cold clouds in north TX over the top of shallow/warm clouds to its immediate south; 5) a band of clouds associated with an upper-level jet stream approaching the northwest coast of Mexico.

While the general cloud patterns of these five regions were rather well matched in all three WRF ensemble members and closely resemble the observations, there are some discrepancies to note. One area of concern is the amount of cloud cover associated with the northeast U.S. low pressure region (\#1). In general, there are more extensive and colder clouds in the observations than shown in any WRF ensemble member. The next region westward (\#2) has an even greater discrepancy, particularly with pixels in the observations of clouds with temperature approximately -10 to $-15^{\circ} \mathrm{C}$. This lack of clouds at these approximate temperatures was also clearly highlighted in Cintineo et al. (2014; their Fig. 6) and represents a challenge to the numerical weather modeling community. We also note the general nature of more isolated and sporadic clouds seen in WRF as compared to the observations across the mountains from CO to OR (\#3). None of the WRF simulations appears to have sufficient horizontal coverage of clouds in this region. The area of deepest convection near the center of the image (\#2) appears more narrow in WRF than in the observations. The low/shallow clouds in region\#4 in south Texas are poorly represented in the model. Lastly, the high-level clouds off the Mexican coast appear to be represented in WRF, however the height or depth may be too low/shallow with insufficient horizontal coverage because the satellite observations show broader and colder cloud tops there.

At first, we were tempted to believe that this general lack of cloud coverage might be just a simple matter of this particular day and time. However, upon deeper analysis, this condition appears to be prevalent throughout the duration of the WRF simulations over the 34 days studied and fully confirms numerous findings in Cintineo et al. (2014). A relative frequency analysis of all 34 simulation days from 
hourly (6- 48) WRF control ensemble member versus satellite observations of IR brightness temperature in $5^{\circ} \mathrm{C}$ intervals is shown in Fig. 6 . The relative frequency of specific ranges of IR temperatures confirms what is seen visually by comparing the observed versus synthetic satellite imagery (Fig. 5). Besides confirming the prior work that included all WRF model grid points against observed IR temperatures, whether clear or cloudy, our analysis isolating only cloudy regions also shows the same general bias, which indicates that many WRF clouds do not extend to theproper height and are too shallow compared to observations. The same analysis was performed on WRF ensemble members $\mathrm{m} 25$ and $\mathrm{m} 30$ and revealed indistinguishable results from the control member shown in Fig. 6 and supports our assertion that analyzing only two days (08 and 18 May) is sufficient to show various discrepancies between the different WRF ensemble members, since we do not have the $\mathrm{m} 30$ member on any other days.

As further evidence of the overall lack of sufficient cloudiness in the model, and its dependence on forecast hour, we analyzed the overall hourly fraction of cloudy points in satellite observations versus WRF when the sun angle was high enough to eliminate any reasonable chance of including clear-sky pixels as clouds. Shown by the red line in Fig. 7 are the two daytime periods of cloud fraction in the GOES satellite data with a 34-day average in the 40-50\% range whereas the WRF control member, shown in blue, was consistently predicting fewer cloudy pixels. The green line labeled "overlap" represents the fraction of the domain that was diagnosed as cloudy in both observations and WRF. Whether or not WRF exhibits similar biases through different seasons has not yet been analyzed.

\section{Shortwave radiation reaching the ground}

The WRF control member data were interpolated using simple bi-linear method to the observational sites for the comparison shown in Fig. 8. When analyzing by the relative frequency of occurrence of specific $100 \mathrm{~W} \mathrm{~m}^{-2}$ intervals of shortwave radiation, we see that the model generally shows an excess of solar radiation reaching the ground when considering all points, cloudy or not (solid color-filled bars). When analyzing only the observational sites found to be cloudy in both the model and observations, there are still too many locations receiving too much radiation in the model. The preponderance of WRF points with more solar radiation than found in observations is a clear indication of the lack of sufficient cloud coverage and/or physical cloud depth and/or the optical treatment of cloud properties in the radiation scheme. When combined with the preceding satellite data analysis, it is clear that some of the cause of excessive incoming solar radiation reaching the surface is due to insufficient areal coverage and thickness of clouds.

While Fig. 8 represents an analysis of all 34 days between the control member and the observations, a subsequent analysis of only the two days including the m30 ensemble member is shown in Fig. 9. Furthermore, the analysis in Fig. 9 represents only those points considered to be cloudy in the observations and each of the WRF ensemble members just as those points are represented by the hatched rectangles in Fig. 8. Among the subtle differences between the WRF ensemble members, the m 25 member clearly has the largest number of points with the lowest radiation values. We interpret this to mean that the improper calculation of snow size too small produces a larger quantity of almost fully opaque clouds. The control experiment has far fewer sites with near fully opaque clouds and the m30 experiment has the fewest and matches the observations rather closely. On the other hand, as the measured incoming solar radiation increases, the control and m30 experiments are generally well-matched while the $\mathrm{m} 25$ experiment is clearly different. Again, due to the smaller radii calculated by $\mathrm{m} 25$, the clouds generally became more opaque so the relative fraction of points with high incoming radiation does appear better in $\mathrm{m} 25$ than either control or $\mathrm{m} 30$, but this is the right answer for the wrong reason as the overall opaqueness of the clouds is likely too great due to the excessively small snow radii. As such, we postulate that if the WRF model was doing a better job forecasting the physical cloud depth and coverage, then it would be very likely that the incoming solar radiation would be over-attenuated because of the snow size calculation being too small in $\mathrm{m} 25$ 
member. On the other hand, the m30 member appears to represent rather well the thickest and most opaque clouds and fully incorporates the microphysics parameterization effective radii of water drops and ice crystals while the control member uses uncoupled a priori assumed sizes.

\section{Surface temperature comparison}

One of the final outcomes of the impacts of clouds and radiation in a numerical weather prediction model is the forecast surface temperature. An example of a single time WRF model forecast error of lowlevel temperature is shown in Fig. 10. Observational data are shown as color-filled and open circles where surface METAR reports are taken at approximately 2500 sites each hour. Sites that were excluded from the analysis are shown by open circles because such location either lacked clouds in the observed satellite data or one or more WRF ensemble members had no clouds at the location. The top panel shows the model minus observations from the control or uncoupled experiment while the middle and lower panels show the differences between control and $\mathrm{m} 25$ then $\mathrm{m} 30$ experiments respectively.

We avoid discussion of the clear-sky regions of the domain, because our changes to WRF are intended to address the interactions between clouds and radiation. While it may seem rather surprising that Fig. 10a clearly shows the preponderance of points in WRF are cooler than the observations, while the incoming solar radiation was previously shown to be too large, this is not due to the cloud forecasts. Instead, the overall model bias with the entire combined package of physics, including LSM, PBL, turbulence, clouds and radiation, leads to an overall slightly negative temperature bias. So regardless of whether clear or cloudy, we found there to be an overall cool bias in the model of roughly $1-2^{\circ} \mathrm{C}$ for the 34 - day period analyzed. Clearly seen in Fig. 10a, the WRF forecast valid at this time is too cool overall in locations with clouds. Notable exceptions are a low-altitude stratus cloud deck found near the OR/WA border and another cloud area near the VA/NC border.

In the next panel, Fig. 10b, the difference in near-surface temperature between the control member and $\mathrm{m} 25$ is shown. As suspected because of attenuating too much solar radiation due to calculating a snow size that is too small, the bias generally worsens as nearly all cloudy areas cool by receiving less radiation than control. However, when switching to the proper snow size calculation, m30 member, you can note that some points now warmed, particularly in the northeast U.S. and near MN and IA. Also note the previously mentioned areas near the WA/OR border and VA/NC border. In the control ensemble member, they were too warm, but the proper cloud physics radiation coupling now reduces the warm temperature bias slightly (additional discussion of this region in the next section).

Rather than considering only one day and time, the overall temperature biases in each ensemble member is confirmed by creating box plots from all time periods of both days seen in Fig. 11. The box plot show that bias appears very similar between control and m30 and more significant differences in $\mathrm{m} 25$. While Fig. 11a shows two days of observed temperature data and WRF forecasted temperature, a similar plot of all days (not shown) exhibit the same biases in control and $\mathrm{m} 25$. In fact, the temperature errors appear relatively small overall with significant overlap between all experiments and the observations. A more focused view of the bias (Fig. 11b) helps to separate the members a little better. The smaller overall snow size contributes to lower solar radiation (confirmed in subsection a and $b$ above) that subsequently results in a stronger cold bias in low-level temperature. Although the box plot does not show a statisticallysignificant change, it supports the earlier statement that the clouds became too opaque.

In general, these results reveal somewhat systematic biases in these WRF simulations with regard to incoming solar radiation and resulting surface temperatures beneath clouds. Although the radiation bias is generally higher in WRF than in the observations, the low-level temperature comparison reveals a cool bias in temperature. One part of the cool bias can be explained by the usually strong near-surface heating at this time of year and the fact that METAR observations are taken near 2 meters whereas the lowest WRF model level at approximately 25 meters was used to calculate the bias. From local noon to late afternoon, when 
the atmospheric lapse rate may approach its dry adiabatic value of $9.8 \mathrm{~K} \mathrm{~km}^{-1}$, the maximum error due to height difference alone would be about $-0.25 \mathrm{~K}$, which could account for part of the bias seen in Fig. 11 . Therefore we speculate that other factors including treatment in the LSM and PBL schemes are likely responsible for the overall cool bias noted in these simulations. In fact, for a number of years in the OU- CAPS Spring Experimental Forecast Program, the MYJ PBL scheme is widely suspected of having a cool and moist bias whereas an alternative PBL scheme from Yonsei University (YSU; Noh et al. 2003) is suspected of having the opposite bias.

To illustrate the temperature bias as a function of forecast hour, Fig. 12 shows the evolution of the three ensemble members during the two daytime periods of the total $48-\mathrm{h}$ forecast. Note from the figure how the three ensemble members are nearly identical at approximately sunrise time and slowly diverge through the first day with noticeably cooler diurnal evolution in the m25 experiment compared to the other two experiments. The same basic progression occurs on the second daytime portion of the forecast as well.

\section{Discussion: "needles in a haystack"}

It was mentioned previously that the coupled and uncoupled experiments have only minor statistical differences for general characteristics of synthetic satellite analysis, solar radiation reaching the surface, and near-surface temperatures, however, there are certain cloud conditions worthy of more detailed investigation. As an example, Fig. 10a revealed a concentrated region of high temperature bias along the Pacific coastline near the border of WA and OR when using the uncoupled experiment that subsequently showed improvement in both the $\mathrm{m} 25$ and $\mathrm{m} 30$ experiments (Fig. 10b,c). This cloudy region was composed of low-altitude stratus clouds without any ice, so this specific region can be examined for the changes due to radiation passing through liquid water clouds only. A glimpse of a single level of WRF liquid water clouds in the region (Figs. 13a-c) shows that the uncoupled WRF experiment has the least LWC whereas the two coupled experiments clearly have more LWC at a single level. A snapshot of visible cloud albedo from GOES satellite is shown in Fig. 13d revealing widespread cloudiness at low altitudes with clear skies at the higher elevations over the Olympic and Cascade mountains. As further evidence, the corresponding WRF synthetic satellite visible albedo images are shown in Fig. 13e- g. Both coupled microphysics-radiation sensitivity experiments show more broad cloud coverage than the uncoupled experiment even though total cloud coverage in this region is still far less than what was observed.

As a second example of nearly the same type, Fig. 14 shows a small region of south Texas where shallow stratocumulus clouds are evident on the satellite image (Fig. 14a). As in Fig. 13, the control experiment has less overall extent of clouds than either the fully coupled $\mathrm{m} 25$ or m30. Clearly the integrated interaction/feedback between microphysics and radiation can give rise to differences in explicitly represented cloud water on NWP time scales. More subtle is the very thin ice cloud in the upper-left corner of each WRF graphic (Fig. 14b- d). The m25 experiment with the smaller snow radii is causing this cloud to appear more opaque than either the control or m30 experiment.

Another region worthy of more detailed investigation is the lower half of circled region\#1 in Fig. 5a. It turns out that this region very well represents the bias of cloud top temperature seen in both Fig. $6 \mathrm{~b}$ and the prior work of Cintineo et al (2014). Recall that there is a model abundance of clouds with tops near 0 to $+20^{\circ} \mathrm{C}$, whereas there is a clear deficit of clouds in the -5 to $-25^{\circ} \mathrm{C}$ temperature regime. The WRF synthetic satelliteimages from each ensemble member do reveal there to be model cloudiness similar in coverage to the observations in this region, but the clouds are modeled too low in the atmosphere (CTT too warm). A future step will be to study the reason why clouds in this portion of the cyclone are not achieving sufficient depths with possible causes related to vertical mixing and entrainment, model grid spacing, microphysical deficiencies or other reasons. 


\section{Conclusions}

Explicit coupling between the Thompson microphysics scheme and the RRTMG radiation scheme for the purpose of calculating cloud optical properties is now available in WRF (v3.5.1 and higher). This new feature combined with the "aerosol aware" version of Thompson and Eidhammer (2014) provides the opportunity to simulate explicitly the aerosol indirect effects in the non-WRF-Chemistry version of the WRF model, which has significant computational advantages.

In addition to describing the coupling method, this study evaluated the impact of the coupling on highresolution convective forecasts. Generally, the coupling showed relatively isolated and modest improvements relative to the uncoupled version of the model, in large part due to the greater overall errors in cloud forecasts present in the model. The coupling showed sensitivity to the treatment of ice/snow size, however, as demonstrated by the varying results between the " $\mathrm{m} 25$ " and " $\mathrm{m} 30$ " experiments. Treating cloud ice/snow as too small or too large can lead to somewhat substantial biases when comparing against observed satellite data.

In general, we conclude that the initial assumptions used to calculate effective radii and cloud optical depth in the uncoupled model were not large sources of error, at least for the mid-latitude clouds studied herein, but the former version of the code excluded the possibility to permit the aerosol indirect effects and were not appropriate for all cloud types. Furthermore, many researchers have begun using WRF and similar NWP models as a regional climate models and the proper coupling of different physical parameterizations should be thoroughly investigated for various couplings.

Acknowledgements. The authors wish to thank David Gill, JimyDudhia, and Wei Wang for their advice and support of various WRF code modifications. NCAR is sponsored by the National Science Foundation. This work was performed as part of NCAR's Short Term Explicit Prediction (STEP) program, which is supported by the National Science Foundation funds for the United States Weather Research Program (USWRP). The OU-CAPS storm-scale ensemble forecasts were produced under the support of NOAA's CSTAR program (NA17RJ1227), using computing resources at the National Science Foundation XSEDE National Institute of Computational Science (NICS) at the University of Tennessee and those at the OU Supercomputing Center for Education and Research (OSCER). J. Otkin was supported by NOAA CIMSS Grant NA10NES4400013 under the GOES-R Risk Reduction Program.

\section{REFERENCES}

Albrecht, B., 1989: Aerosols, cloud microphysics, and fractional cloudiness, Science, 245, 1227- 1230.

Barlage, M., F. Chen, M. Tewari, K. Ikeda, D. Gochis, J. Dudhia, R. M. Rasmussen, B. Livneh, M. Ek, K. Mitchell, 2010: Noah land surface model modifications to improve snowpack prediction in the Colorado Rocky Mountains. J. Geophys. Res.,115:D22.

Bikos, D., and Coauthors, 2012: Synthetic satellite imagery for real-time high-resolution model evaluation. Wea. Forecasting, 27, 784-795.

Boucher, O., S. E. Schwartz, T. P. Ackerman, T. L. Anderson, B. Bergstrom, B. Bonnel, P. Chylek, A. Dahlback, Y. Fouquart, Q. Fu, R. N. Halthore, J. M. Haywood, T. Iversen, S. Kato, S. Kinne, A. Kirkevåg, K. R. Knapp, A. Lacis, I. Laszlo, M. I. Mishchenko, S. Nemesure, V. Ramaswamy, D. L. Roberts, P. Russell, M. E. Schlesinger, G. L. Stephens, R. Wagener, M. Wang, J. Wong, and F. Yang, 1998: Intercomparison of models representing direct shortwave radiative forcing by sulfate aerosols. J. Geophys. Res., 103, 16979-16998.

Bryan, G. H., J. C. Wyngaard, J. M. Fritsch, 2003: Resolution Requirements for the Simulation of Deep Moist Convection. Mon. Wea. Rev., 131, 2394-2416.

Chaboureau, J.-P., and J.-P. Pinty, 2006: Validation of a cirrus parameterization with Meteosat Second Generation observations. Geophys. Res. Lett.,33, L03815. 
Chen, F., and J. Dudhia, 2001: Coupling an advanced land-surface/ hydrology model with the Penn State/ NCAR MM5 modeling system. Part I: Model description and implementation. Mon. Wea. Rev.,129, 569-585.

Chou, M.-D., M. J. Suarez, C.-H. Ho, M. M.-H. Yah, and K.-T. Lee, 1998: Parameterizations for cloud overlapping and shortwave single-scattering properties for use in general circulation and cloud ensemble models. $J$. Climate, 11, 202-214.

Cintineo, R., J. A. Otkin, M. Xue, and F. Kong, 2014: Evaluating the performance of planetary boundary layer and cloud microphysical parameterization schemes in convection-permitting ensemble forecasts using synthetic GOES-13 satellite observations. Mon. Wea. Rev., 142, 163-182.

Clark, A. J., and Coauthors, 2012: An overview of the 2010 Hazardous Weather Testbed Experimental Forecast Program Spring Experiment. Bull. Amer. Meteor. Soc.,93, 55-74.

—, M. C., Coniglio, B. E. Coffer, G. Thompson, M. Xue, and F. Kong, 2015: Sensitivity of 24-h Forecast Dryline Position and Structure to Boundary Layer Parameterizations in Convection-Allowing WRF Model Simulations. Wea. Forecasting, 30, 613- 638.

Cox, G. P., 1988: Modelling precipitation in frontal rainbands. Quart. J. Roy. Meteor. Soc., 114, 115-127.

Diamond, H. J., T. R. Karl, M. A. Palecki, C. B. Baker, J. E. Bell, R. D. Leeper, D. R. Easterling, J. H. Lawrimore, T. P. Meyers, M. R. Helfert, G. Goodge, and P. W. Thorne, 2013: U.S. Climate Reference Network after one decade of operations: status and assessment. Bull. Amer. Meteor. Soc.,94, 489-498.

Dudhia, J., 1989: Numerical study of convection observed during the winter monsoon experiment using a mesoscale two-dimensional model. J. Atmos. Sci., 46, 3077-3107.

Feltz, W. F., K. M. Bedka, J. A. Otkin, T. Greenwald, and S. A. Ackerman, 2009: Understanding satellite-observed mountain wave signatures using high-resolution numerical model data. Wea. Forecasting, 24, 76-86.

Field, P. R., R. J. Hogan, P. R. A. Brown, A. J. Illingworth, T. W. Choularton, and R. J. Cotton, 2005: Parameterization of ice-particle size distributions for mid-latitude stratiform cloud. Quart. J. Roy. Meteor. Soc., 131, 1997-2017.

Fouquart, Y., J. Buriez, M. Herman, and R. Kandel, 1990: The influence of clouds on radiation: A climate-modeling perspective. Rev. Geophys., 28, 145-166.

Fu, Q., 1996: An accurate parameterization of the solar radiative properties of cirrus clouds for climate models. $J$. Climate, 9, 2058-2082.

- P. Yang, and W. B. Sun, 1998: An accurate parameterization of the infrared radiative properties of cirrus clouds for climate models. J. Climate, 11, 2223-2237.

Grasso, L. D., and T. Greenwald, 2004: Analysis of 10.7- $\mu \mathrm{m}$ brightness temperatures of a simulated thunderstorm with two-moment microphysics. Mon. Wea. Rev., 132, 815-825.

—, M. Sengupta, J. F. Dostalek, R. Brummer, and M. DeMaria, 2008: Synthetic satellite imagery for current and future environmental satellites. Int. J. Remote Sens., 29, 4373-4384.

—, M. Sengupta, and M. DeMaria, 2010: Comparison between observed and synthetic 6.5 and $10.7 \mu \mathrm{m}$ GOES-12 imagery of thunderstorms that occurred on 8 May 2003. Int. J. Remote Sens., 31, 647-663.

— D. T. Lindsey, K.-S. Sunny Lim, A. J. Clark, D. Bikos, and S. R. Dembek, 2014: Evaluation of and suggested improvements to the WSM6 microphysics in WRF-ARW using synthetic and observed GOES-13 imagery. Mon. Wea. Rev., 142, 3635-3650.

Grell, G. A., S. E. Peckham, R. Schmitz, S. A. McKeen, G. Frost, W. C. Skamarock, and B. Eder, 2005: Fully coupled online chemistry within the WRF model. Atmos. Environ.,39, 6957-6975

Heidinger, A. K., C. O’Dell, R. Bennartz, and T. Greenwald, 2006: The successive-order-of-interaction radiative transfer model. Part I: Model development. J. Appl. Meteor. Climatol.,45, 1388-1402.

Houze, R. A., P. V. Hobbs, P. H. Herzegh, and D. B. Parsons, 1979: Size distributions of precipitation particles in frontal clouds. J. Atmos. Sci., 36, 156-162.

Hu, Y. X., and K. Stamnes, 1993: An accurate parameterization of the radiative properties of water clouds suitable for use in climate models. J. Clim.,6, 728-742.

Iacono, M.J., E.J. Mlawer, S.A. Clough and J.-J. Morcrette, 2000: Impact of an improved longwave radiation model, RRTM, on the energy budget and thermodynamic properties of the NCAR community climate mode, CCM3. J. Geophys. Res., 105, 14873-14890.

IPCC, 2007: Climate Change 2007: The physical science basis. Contribution of working group I to the fourth assessment report of the Intergovernmental Panel on Climate Change [Solomon, S., D. Qin, M. Manning, Z. Chen, M. Marquis, K.B. Averyt, M. Tignor and H.L. Miller (eds.)]. Cambridge University Press, Cambridge, United 
Kingdom and New York, NY, USA, 996 pp.

Janjic, Z. I., 2002: Nonsingular implementation of the Mellor-Yamada Level 2.5 Scheme in the NCEP Meso model. NCEP Office Note No. 437, NOAA/NWS, 61 pp.

Jankov, I., L. D. Grasso, M. Sengupta, P. J. Neiman, D. Zupanski, M. Zupanski, D. Lindsey, D. W. Hillger, D. L. Birkenheuer, R. Brummer, and H. Yuan, 2011: An Evaluation of Five ARW-WRF Microphysics Schemes Using Synthetic GOES Imagery for an Atmospheric River Event Affecting the California Coast. J. Hydrometeor, 12, 618-633.

Karlsson, K.-G., 1996: Validation of modeled cloudiness using satellite-estimated cloud climatologies. Tellus, 48A, 767-785.

Kong, F., and Coauthors, 2014: CAPS Storm-Scale Ensemble Forecasting System: Impact of IC and LBC perturbations. Preprints, 26th WAF/22nd NWP Conf., Atlanta, GA, Amer. Meteor.Soc., Paper 119.

Lopez, P., K. Finkele, P. Clark, and P. Mascart, 2003: Validation and intercomparison of three FASTEX cloud systems: Comparison with coarse-resolution simulations. Quart. J. Roy. Meteor. Soc., 129, 1841-1871.

Mellor, G. L., and T. Yamada, 1982: Development of a turbulence closure model for geophysical fluid problems. Rev. Geophys., 20, 851-875.

Meyers, M. P., R. L. Walko, J. Y. Harrington, and W. R. Cotton, 1997: New RAMS cloud microphysics parameterization. Part II: The two-moment scheme. Atmos. Res., 45, 3-39.

Milbrandt, J. A., and M. K. Yau, 2005: A multimoment bulk microphysics parameterization. Part I: Analysis of the role of the spectral shape parameter. J. Atmos. Sci., 62, 3051-3064.

Mlawer, E. J., S. J. Taubman, P. D. Brown, M. J. Iacono, and S. A. Clough, 1997: Radiative transfer for inhomogeneous atmospheres: RRTM, a validated correlated-k model for the longwave. J Geophys. Res.102, doi: 10.1029/97JD00237.

Morrison, H., and J. O. Pinto, 2005: Mesoscale modeling of springtime arctic mixed-phase stratiform clouds using a new two-moment bulk microphysics scheme. J. Atmos. Sci., 62, 3683-3704.

- andMilbrandt, J. A., 2015: Parameterization of Cloud Microphysics Based on the Prediction of Bulk Ice Particle Properties. Part I: Scheme Description and Idealized Tests. J. Atmos. Sci., 72, 287- 311.

Noh, Y., W. G. Cheon, S.-Y. Hong, and S. Raasch, 2003: Improvement of the K-profile model for the planetary boundary layer based on large eddy simulation data. Bound.-Layer Meteor., 107, 401-427.

O'Dell, C. W., A. K. Heidinger, T. Greenwald, P. Bauer, and R. Bennartz, 2006: The successive-order-of-interaction radiative transfer model. Part II: Model performance and applications. J. Appl. Meteor. Climatol.,45, 1403-1413.

Otkin, J. A., D. J. Posselt, E. R. Olson, H.-L. Huang, J. E. Davies, J. Li, and C. S. Velden, 2007: Mesoscale numerical weather prediction models used in support of infrared hyperspectral measurement simulation and product algorithm development. J. Atmos. Oceanic Technol.,24, 585-601.

— and T. J. Greenwald, 2008: Comparison of WRF model-simulated and MODIS-derived cloud data. Mon. Wea. Rev., 136, 1957-1970.

— T. J. Greenwald, J. Sieglaff, and H.-L. Huang, 2009: Validation of a large-scale simulated brightness temperature dataset using SEVIRI satellite observations. J. Appl. Meteor. Climatol.,48, 1613-1626.

Rikus, L., 1997: Application of a scheme for validating clouds in an operational global NWP model. Mon. Wea. Rev., 125, 1615-1637.

Skamarock, W. C., and J. B. Klemp, 2008: A time-split non-hydrostatic atmospheric model for weather research and forecasting applications. J. Comput. Phys., 227, 3465-3485.

Slingo, A., 1989: A GCM parameterization for the shortwave radiative properties of water cloud. J. Atmos. Sci., 46, 1419- 1427.

Stensrud, D. J., 2007: Parameterization Schemes: Keys to Understanding Numerical Weather Prediction Models. Cambridge Univ. Press, 459pp.

Stephens, G. L., S. C. Tsay, P. W. Stackhouse, and P. J. Flatau, 1990: The relevance of the microphysical and radiative properties of cirrus clouds to climate and climatic feedback. J. Atmos. Sci., 47, 1742- 1753.

Sun, Z., and L. Rikus, 2004: Validating model clouds and their optical properties using geostationary satellite imagery. Mon. Wea. Rev., 132, 2006-2020.

Tao, W.-K., J.-P. Chen, Z. Li, C. Wang, and C. Zhang, 2012: Impact of aerosols on convective clouds and precipitation, Rev. Geophys., 50, RG2001.

Thompson, G., R. M. Rasmussen, and K. Manning, 2004: Explicit forecasts of winter precipitation using an improved 
bulk microphysics scheme. Part I: Description and sensitivity analysis. Mon. Wea. Rev., 132, 519-542.

—, P. R. Field, R. M. Rasmussen, and W. D. Hall, 2008: Explicit forecasts of winter precipitation using an improved bulk microphysics scheme. Part II: Implementation of a new snow parameterization. Mon. Wea. Rev., 136, 5095- 5115.

— and T. Eidhammer, 2014: A study of aerosol impacts to clouds and precipitation development in a large winter cyclone. J. Atmos. Sci., 71, 3636- 3658.

Tselioudis, G., and C. Jakob, 2002: Evaluation of midlatitude cloud properties in a weather and a climate model: Dependence on dynamic regime and spatial resolution. J. Geophys. Res., 107, 4781.

Twomey, S., 1974: Pollution and the planetary albedo. Atmos. Environ.,8, 1251-1256.

Wood, R., 2012: Stratocumulus Clouds. Mon. Wea. Rev.,140, 2373-2423.

Woods, C. P., M. T. Stoelinga, and J. D. Locatelli, 2007: The IMPROVE-1 storm of 1-2 February 2001. Part III: Sensitivity of a mesoscale model simulation to the representation of snow particle types and testing of a bulk microphysical scheme with snow habit prediction. J. Atmos. Sci., 64, 3927- 3948.

Xue, M., and Coauthors, 2010: CAPS realtime storm scale ensemble and high resolution forecasts for the NOAA Hazardous Weather Testbed 2010 Spring Experiment. Preprints, 25th Conf. on Severe Local Storms, Denver, CO, Amer. Meteor. Soc., Paper 7B.3.

Zamora, R. J., E. G. Dutton, M. Trainer, S. A. McKeen, J. M. Wilczak, and Y.-T. Hou, 2005: The Accuracy of Solar Irradiance Calculations Used in Mesoscale Numerical Weather Prediction. Mon. Wea. Rev., 133, 783-792. 


\section{Figures}

Figure01
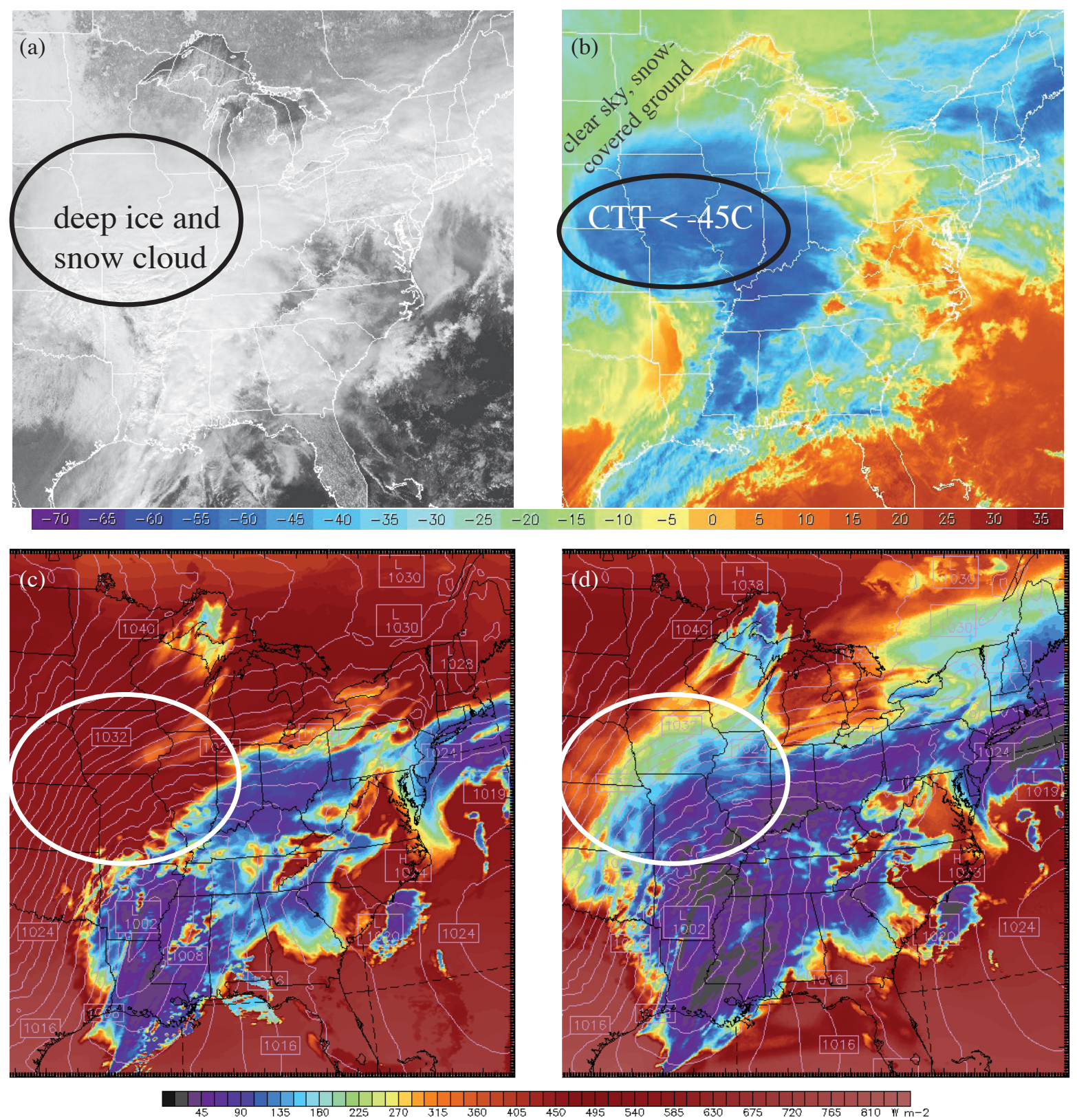


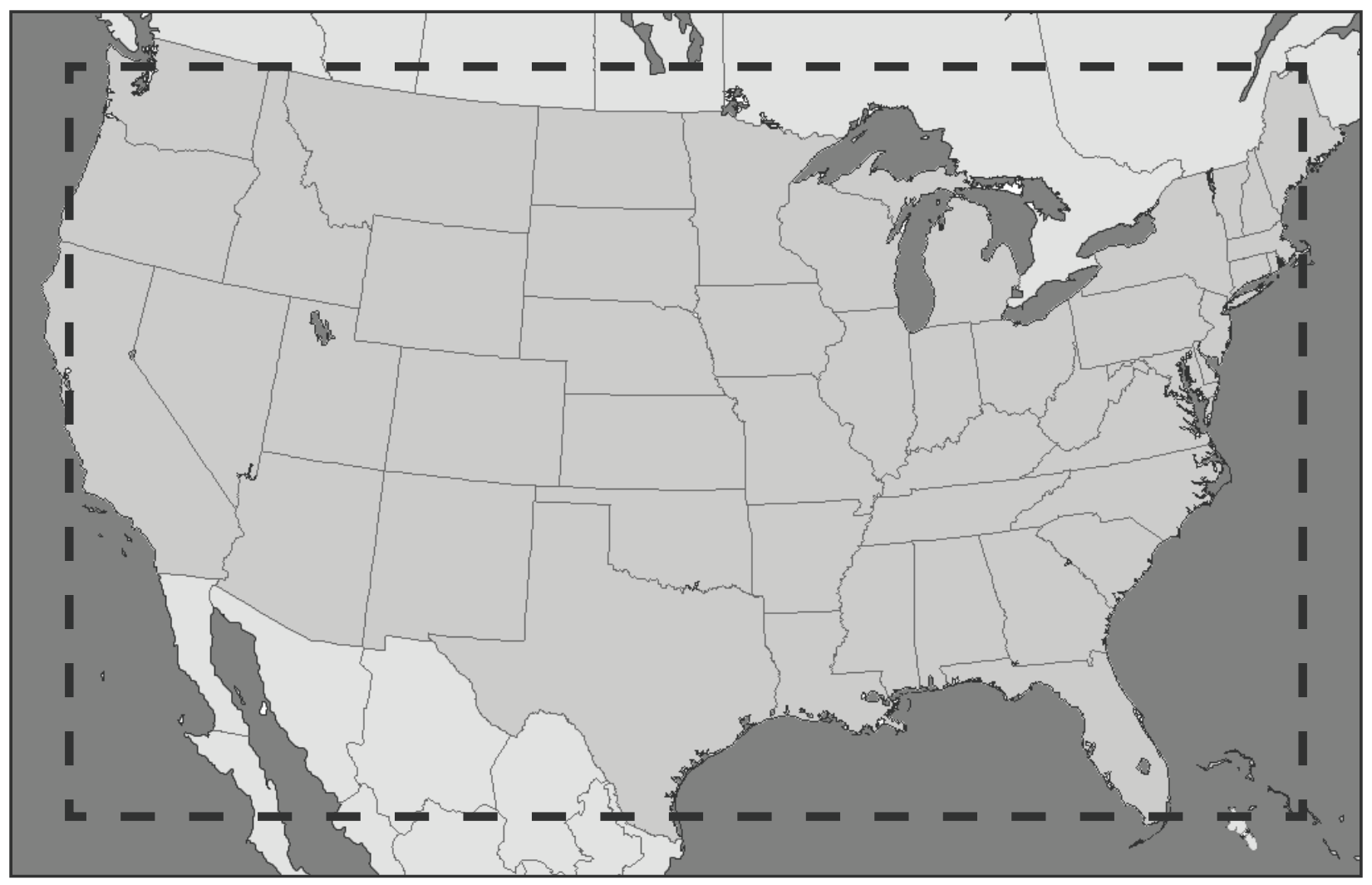




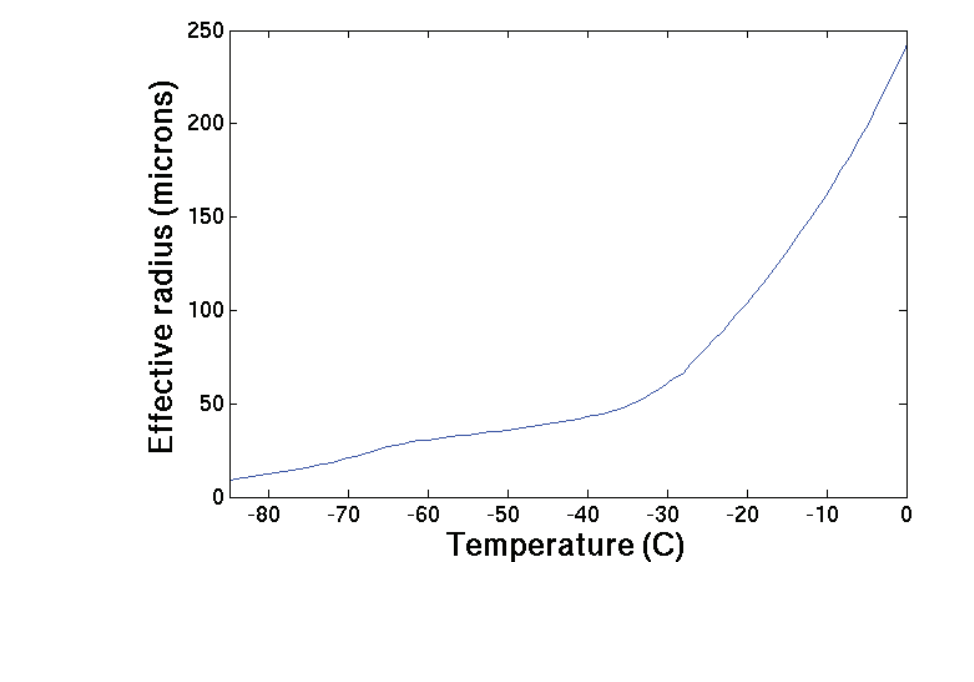

Figure03

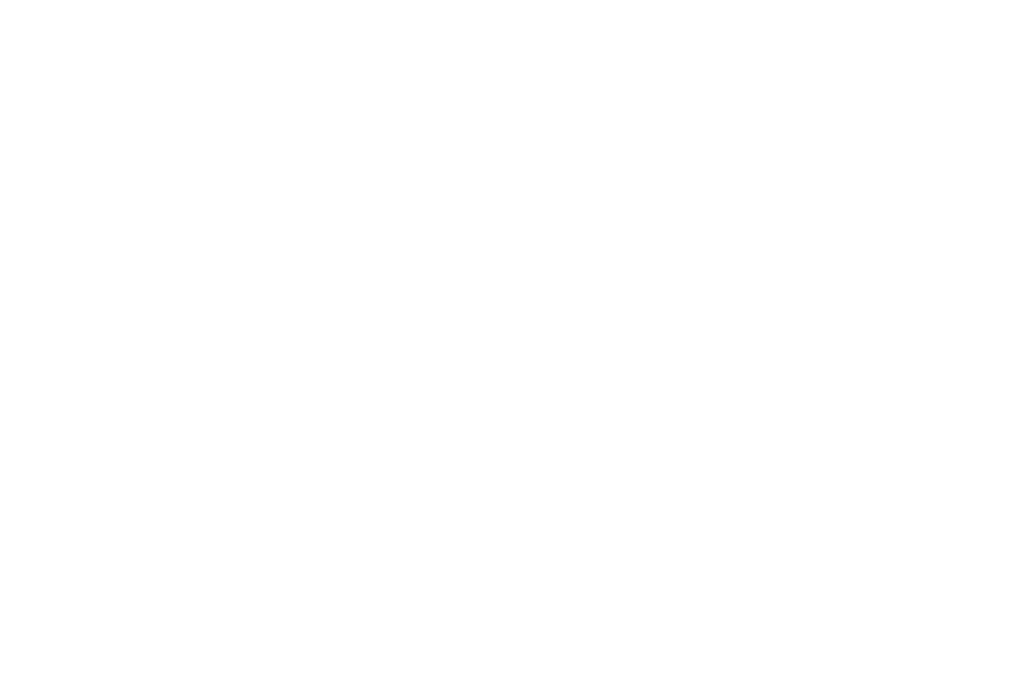

\section{Eigure03}

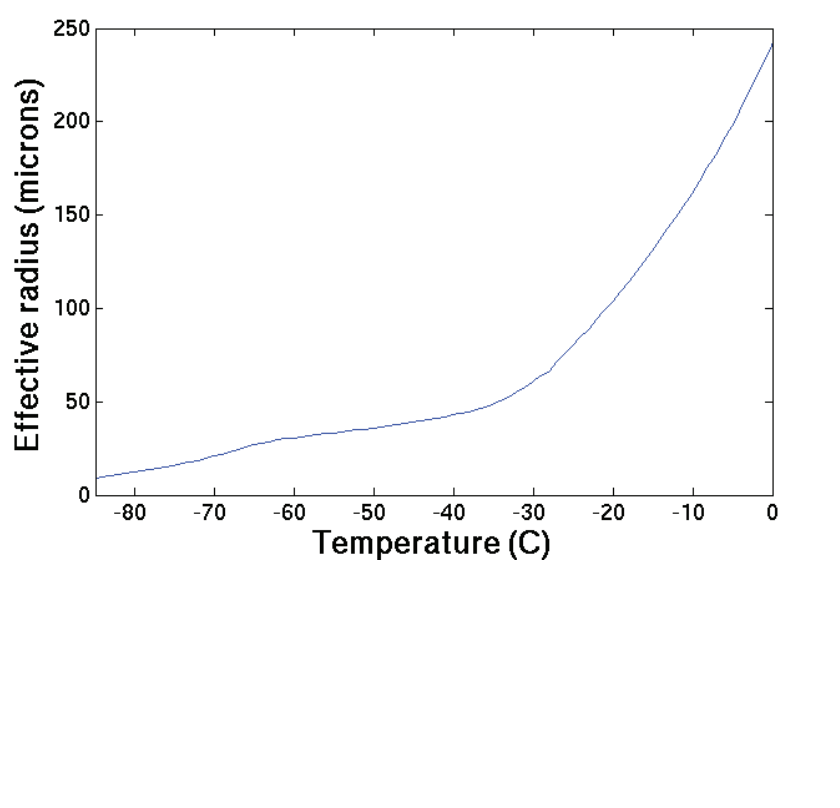

\section{Fi}
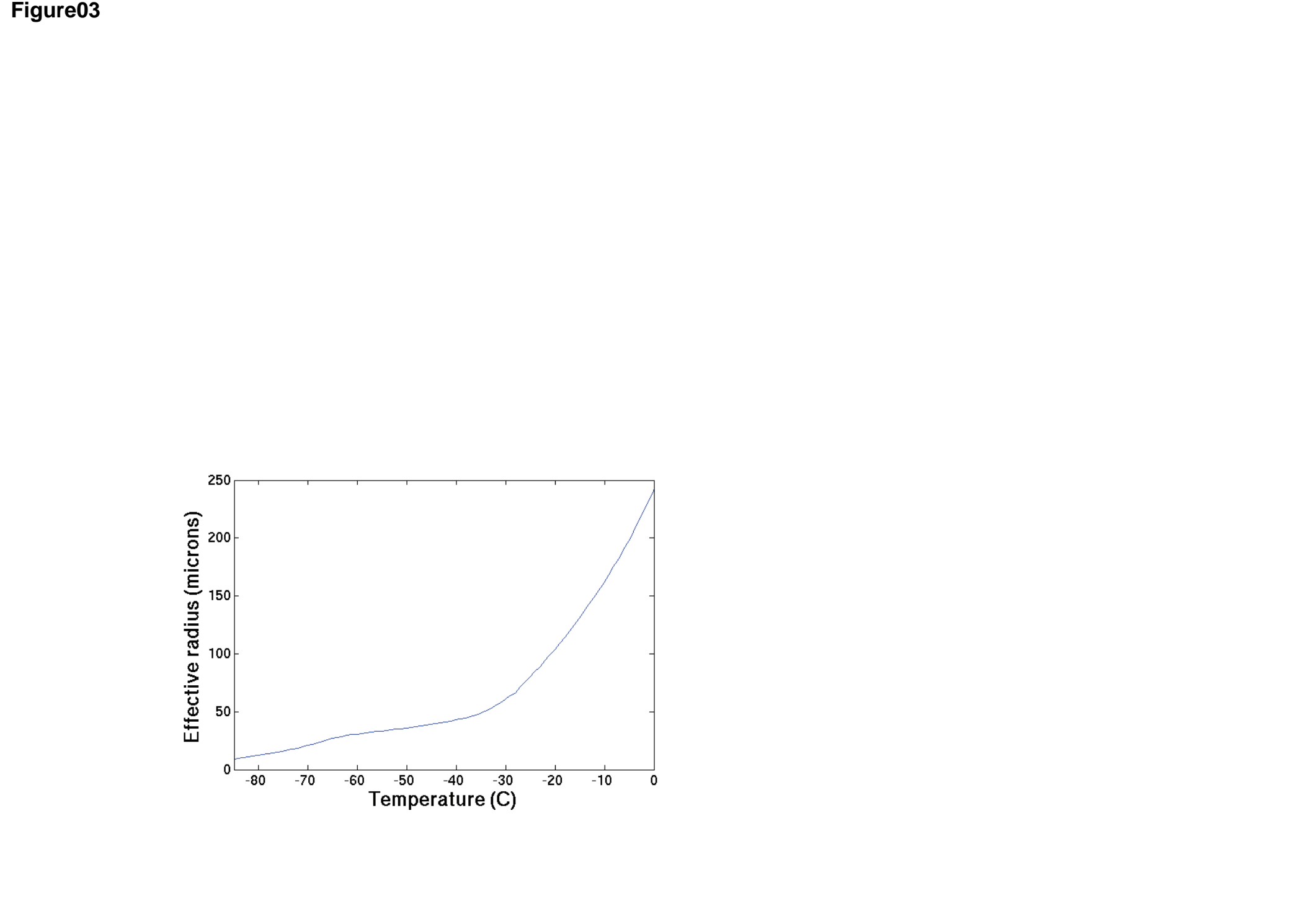


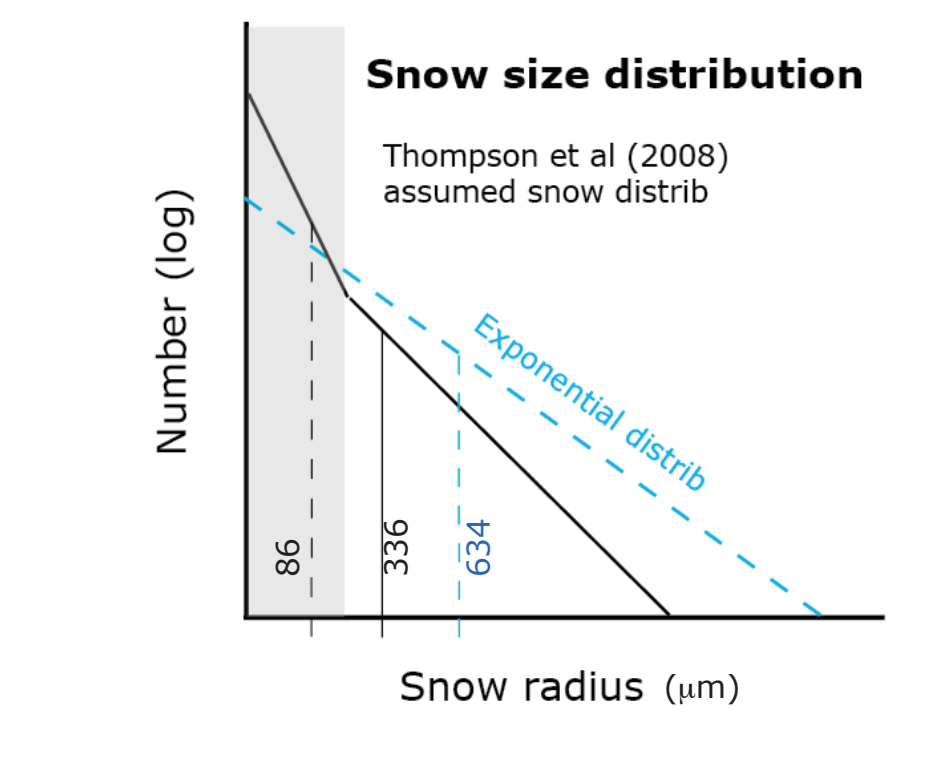

Figure04

Snow radius $(\mu \mathrm{m})$

Figure04

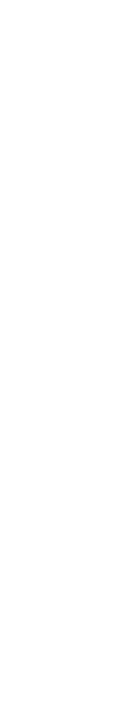



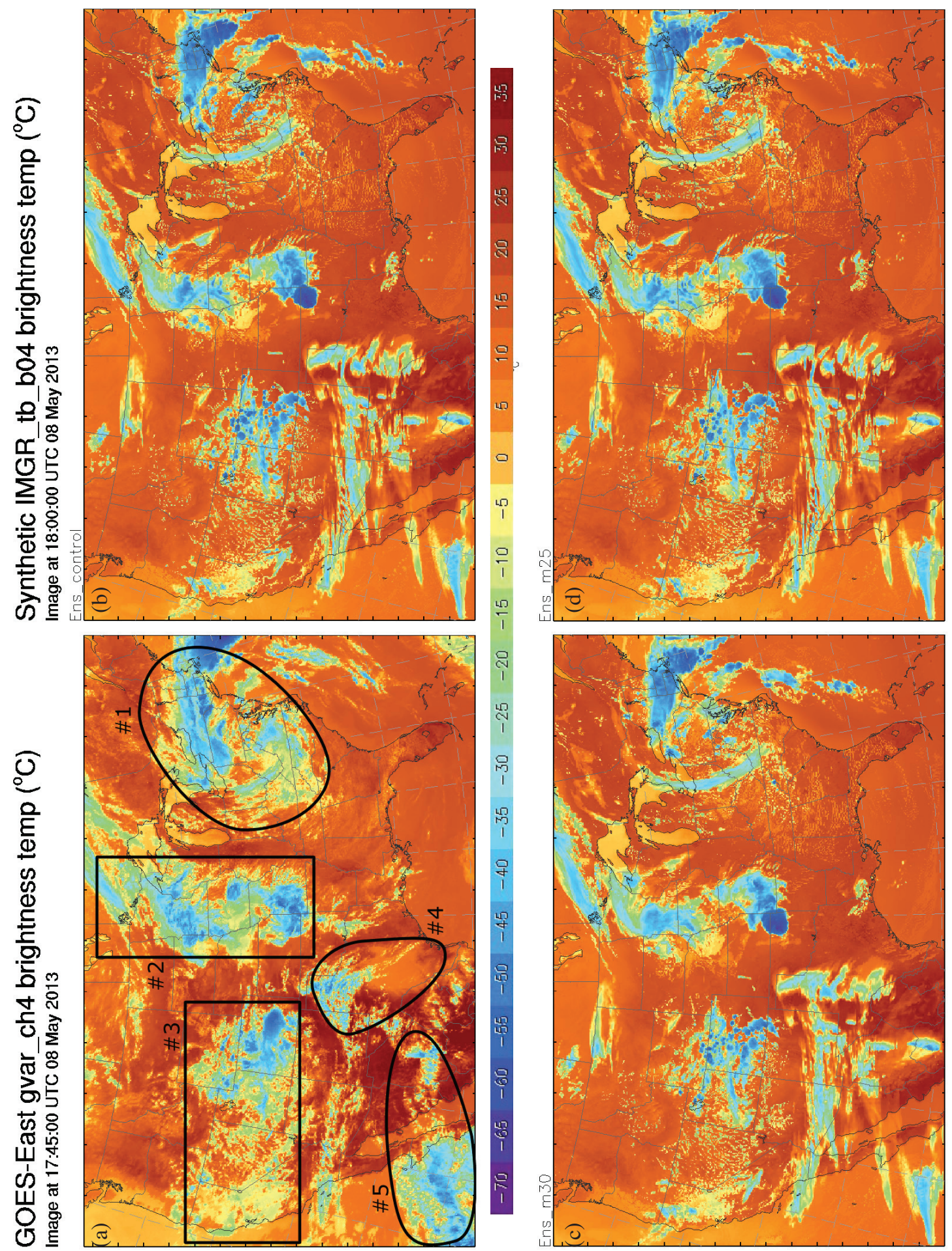
(b)
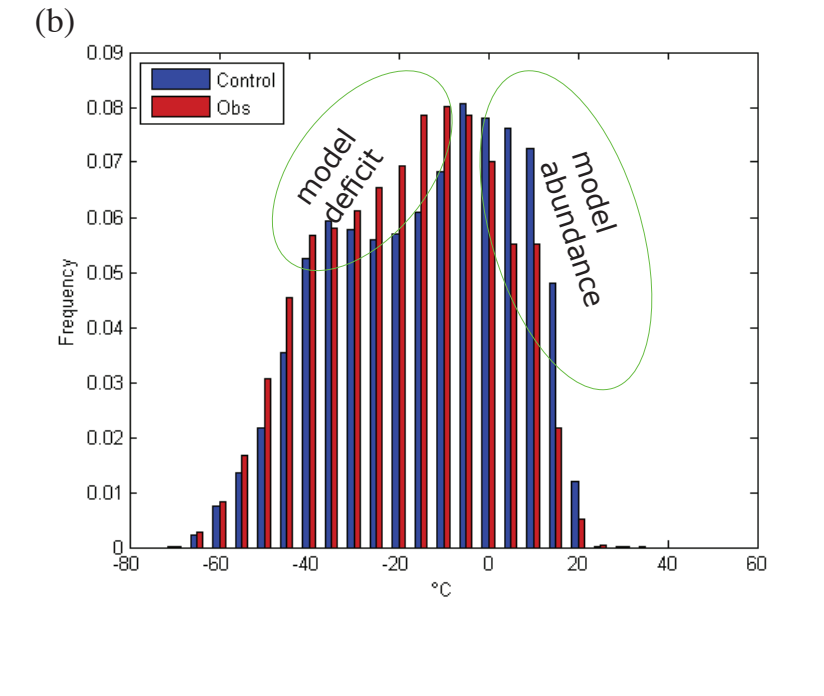

(a)

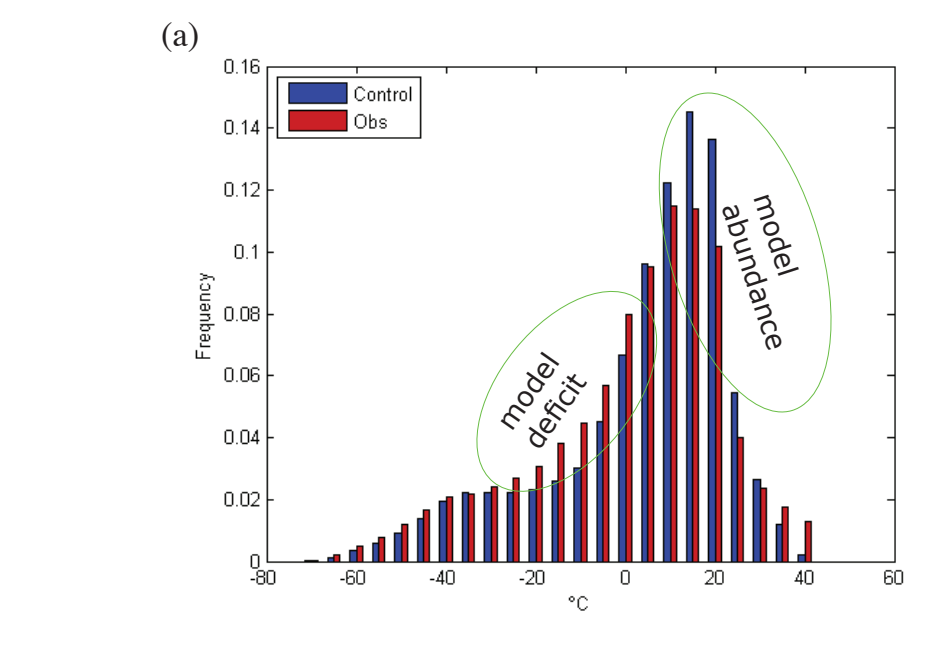

Figure06
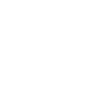


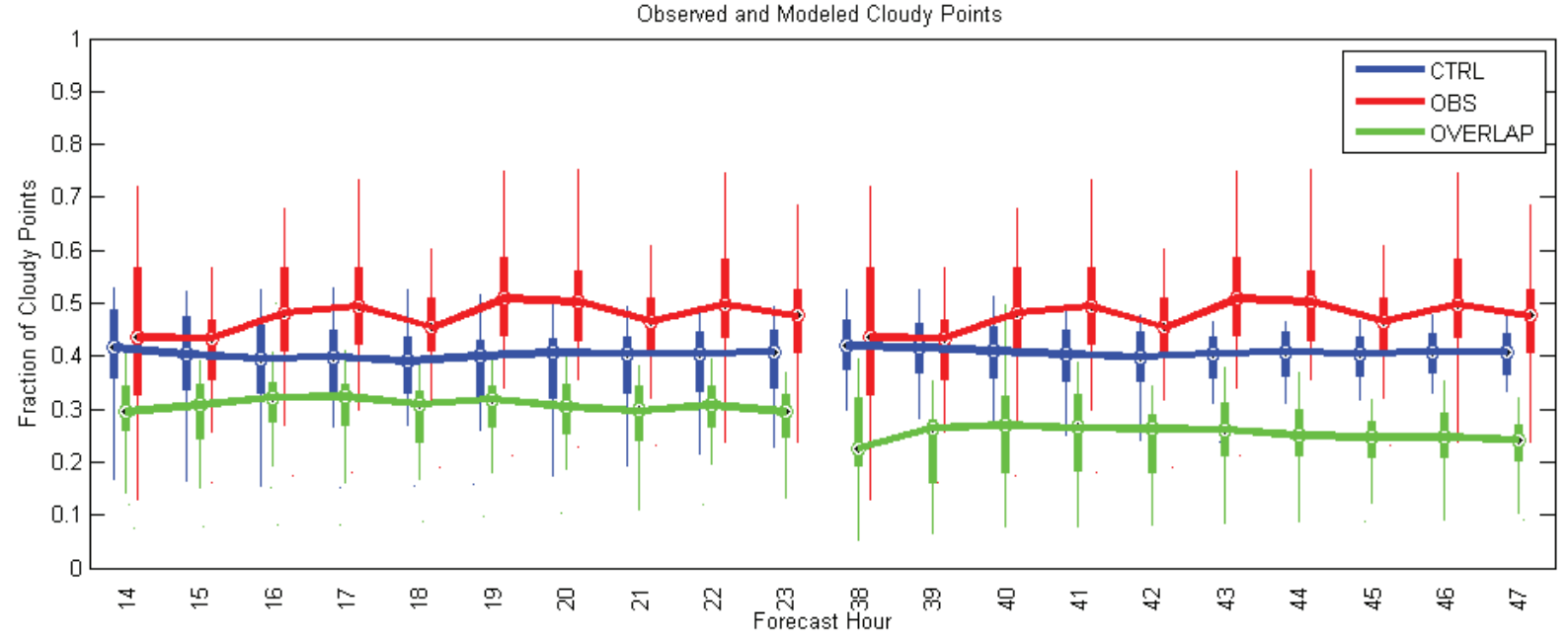

Figure07

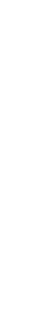




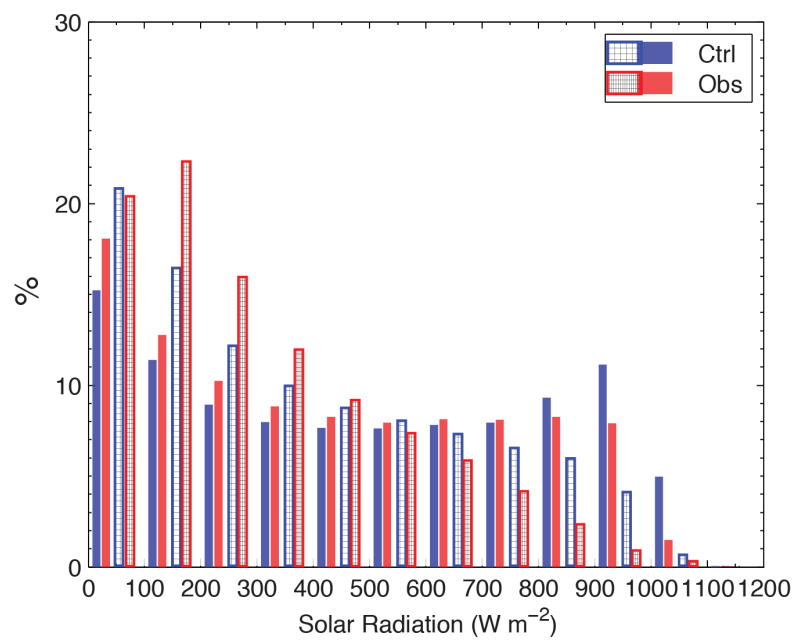

Figure08

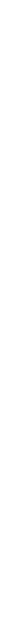


Difference in near-sfc temperature (C) between METAR and WRF in cloudy area (Uncoupled) 08 May 2013 18:00 UTC

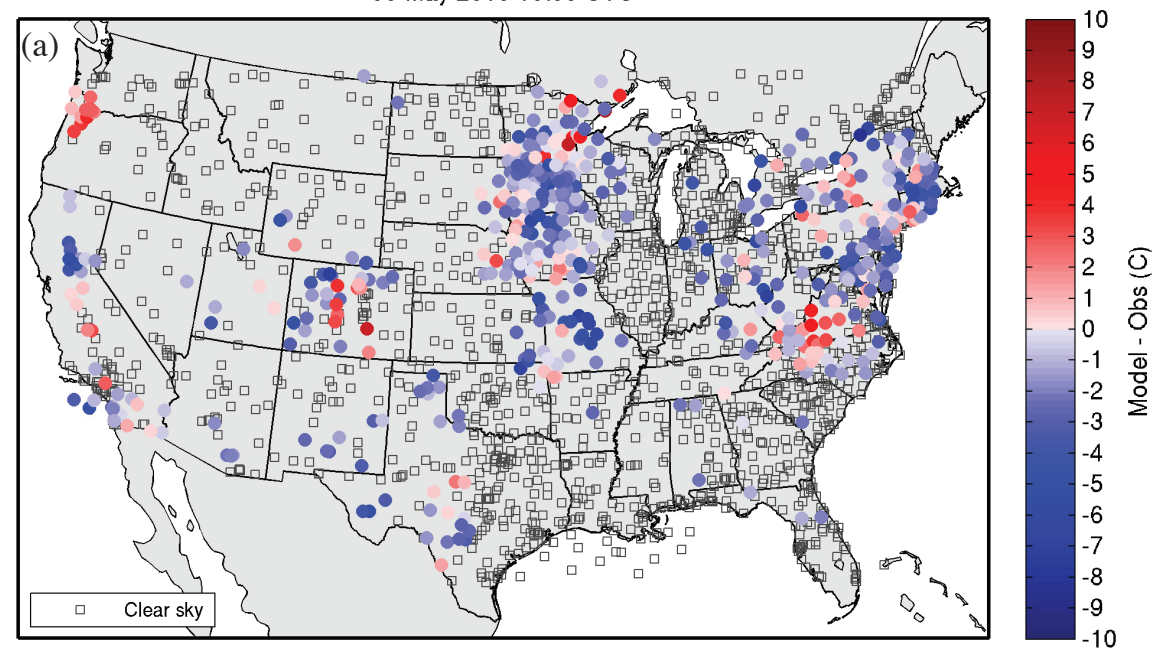

Difference in near-sfc temperature (C) between CTRL(Uncoupled) and m25 (coupled) WRF 08 May 2013 18:00 UTC

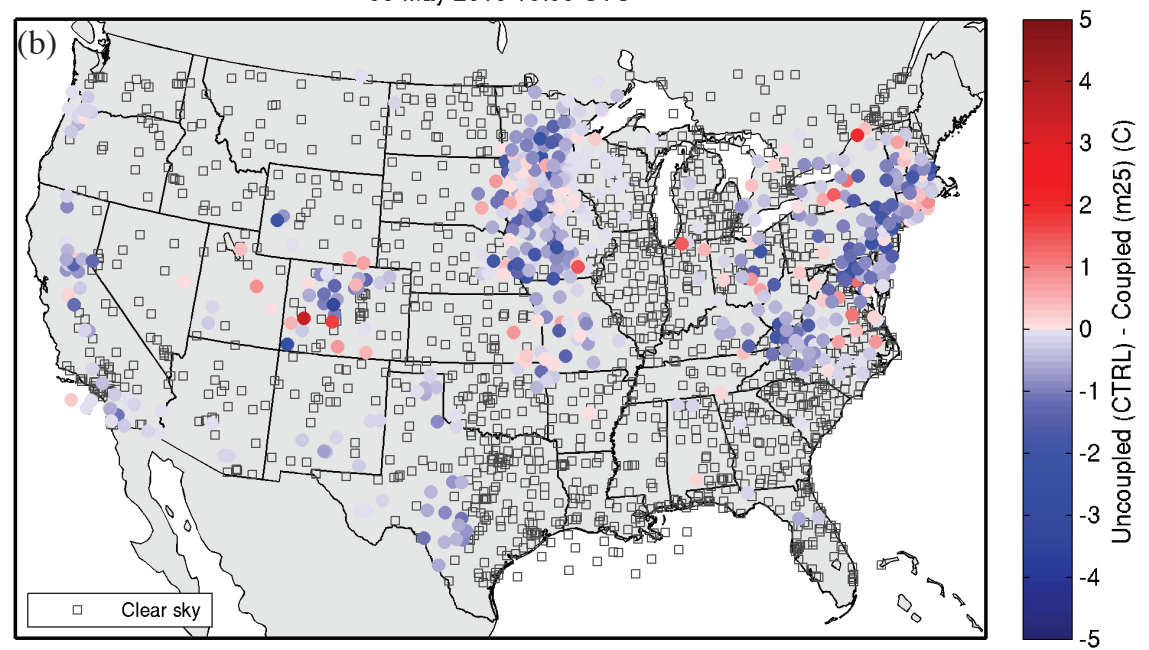

Difference in near-sfc temperature (C) between CTRL (Uncoupled) and $\mathrm{m} 30$ 08 May 2013 18:00 UTC

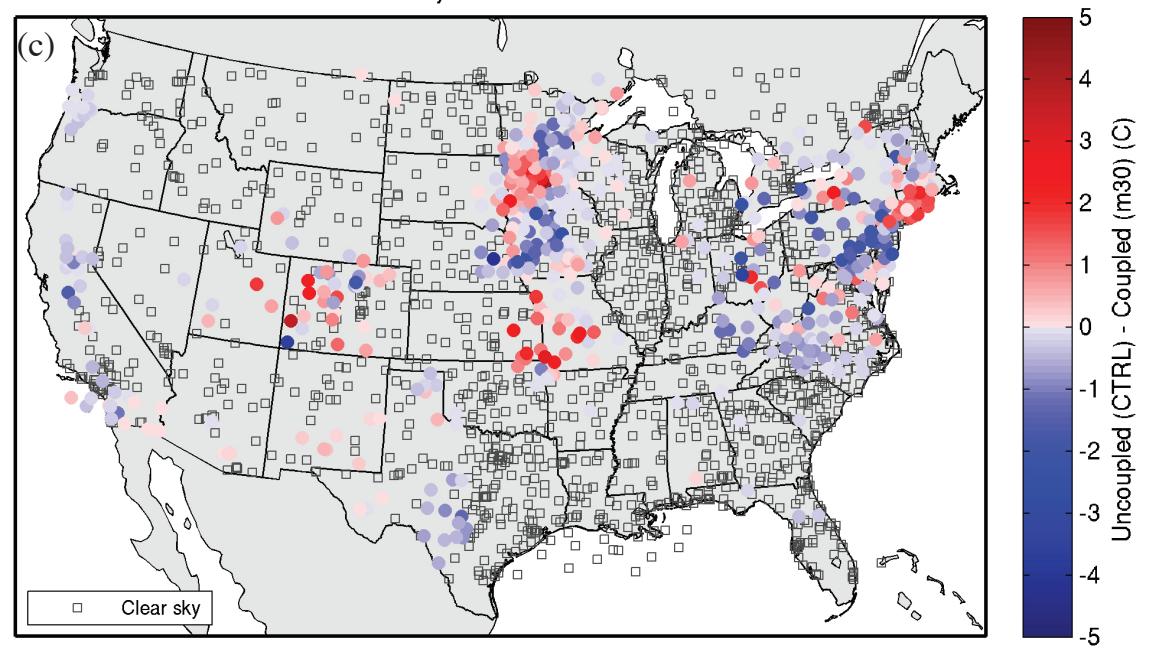



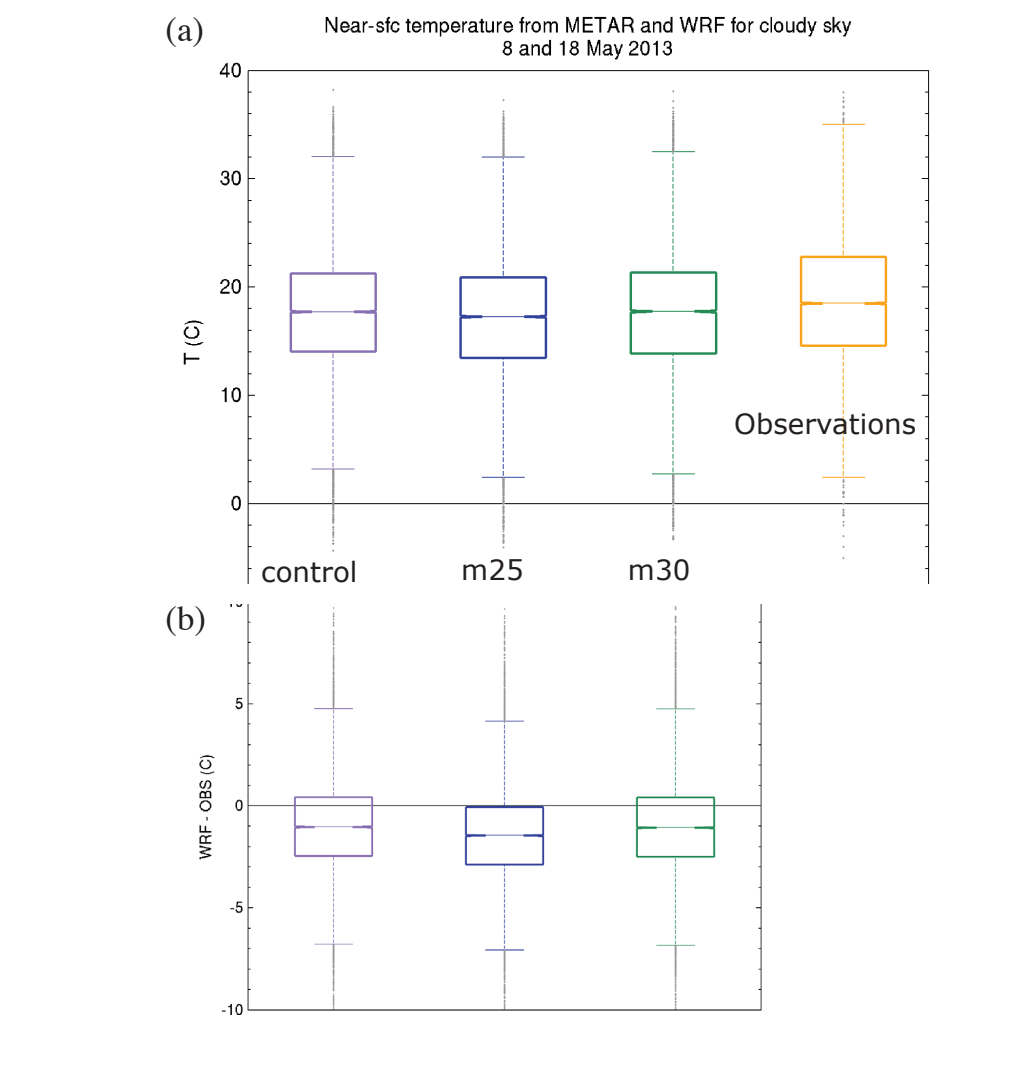

\section{Figure11}
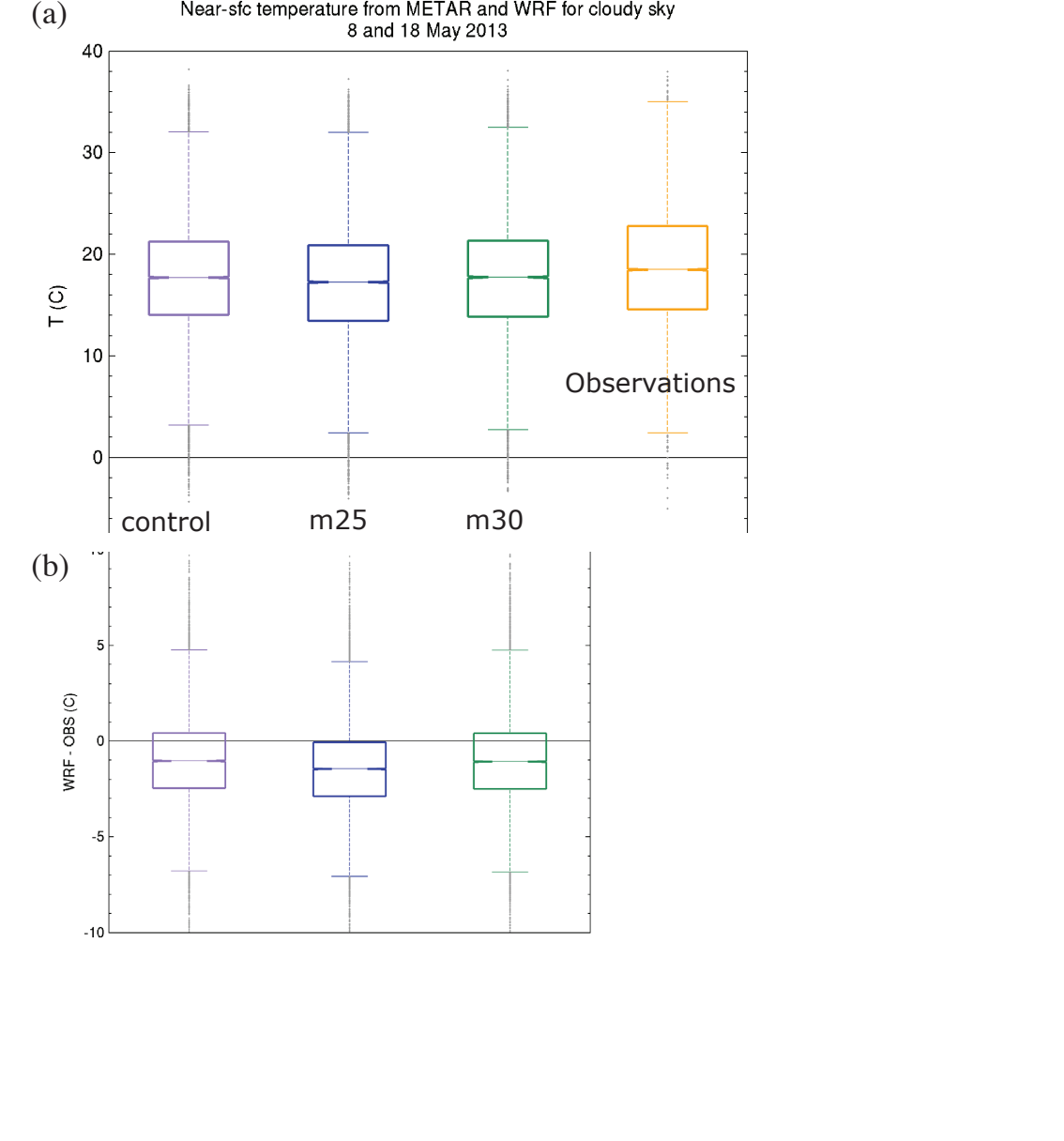

.
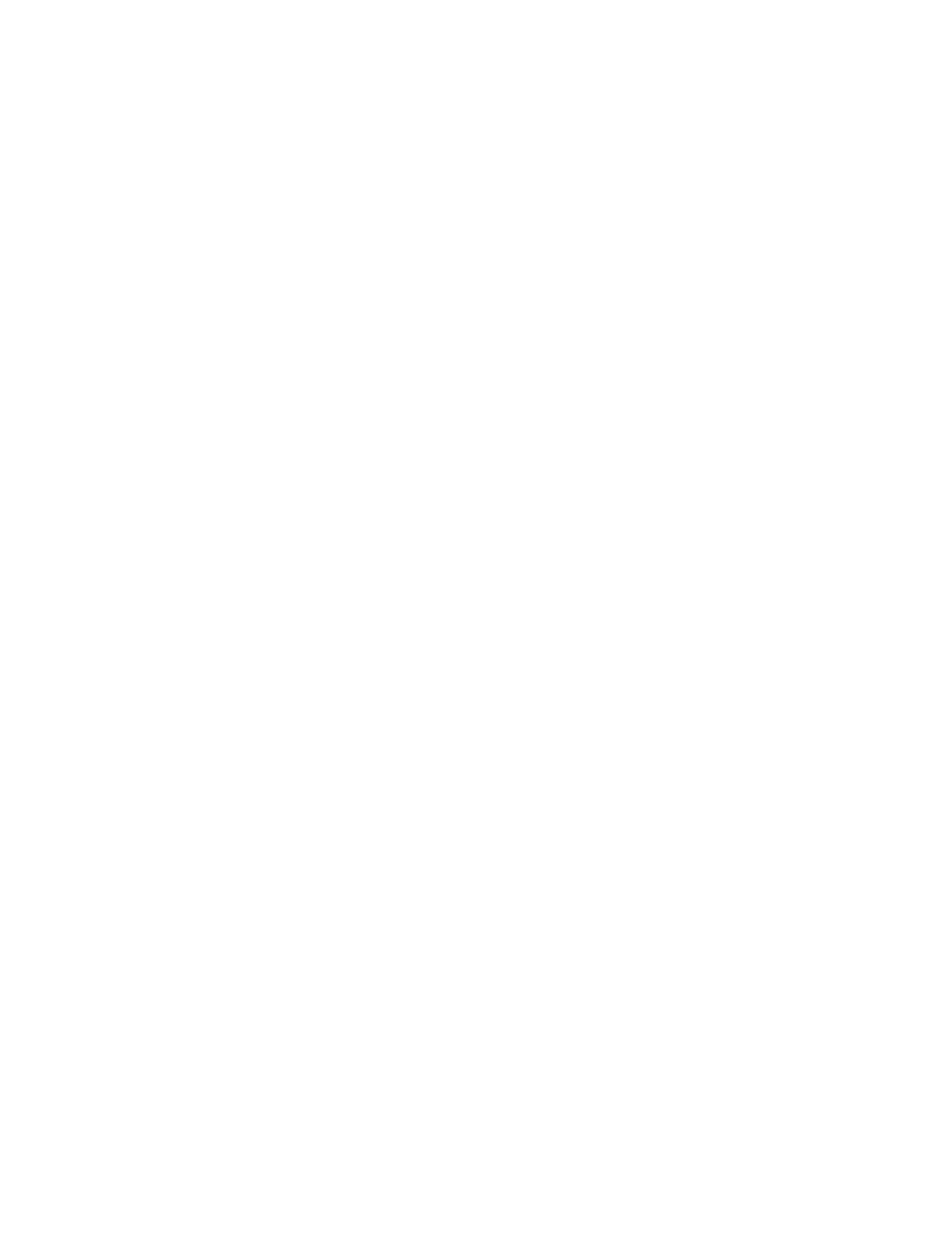
-
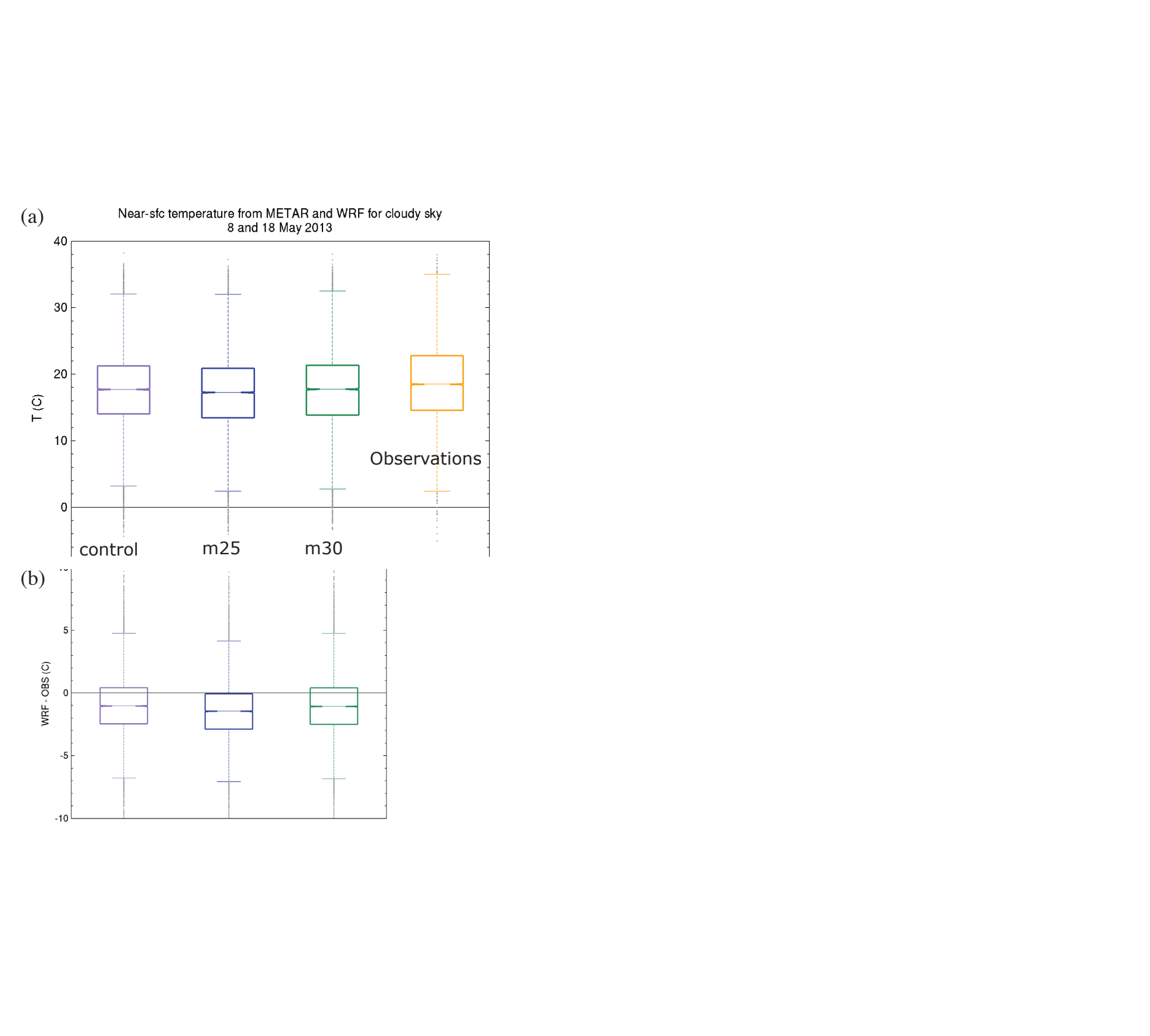


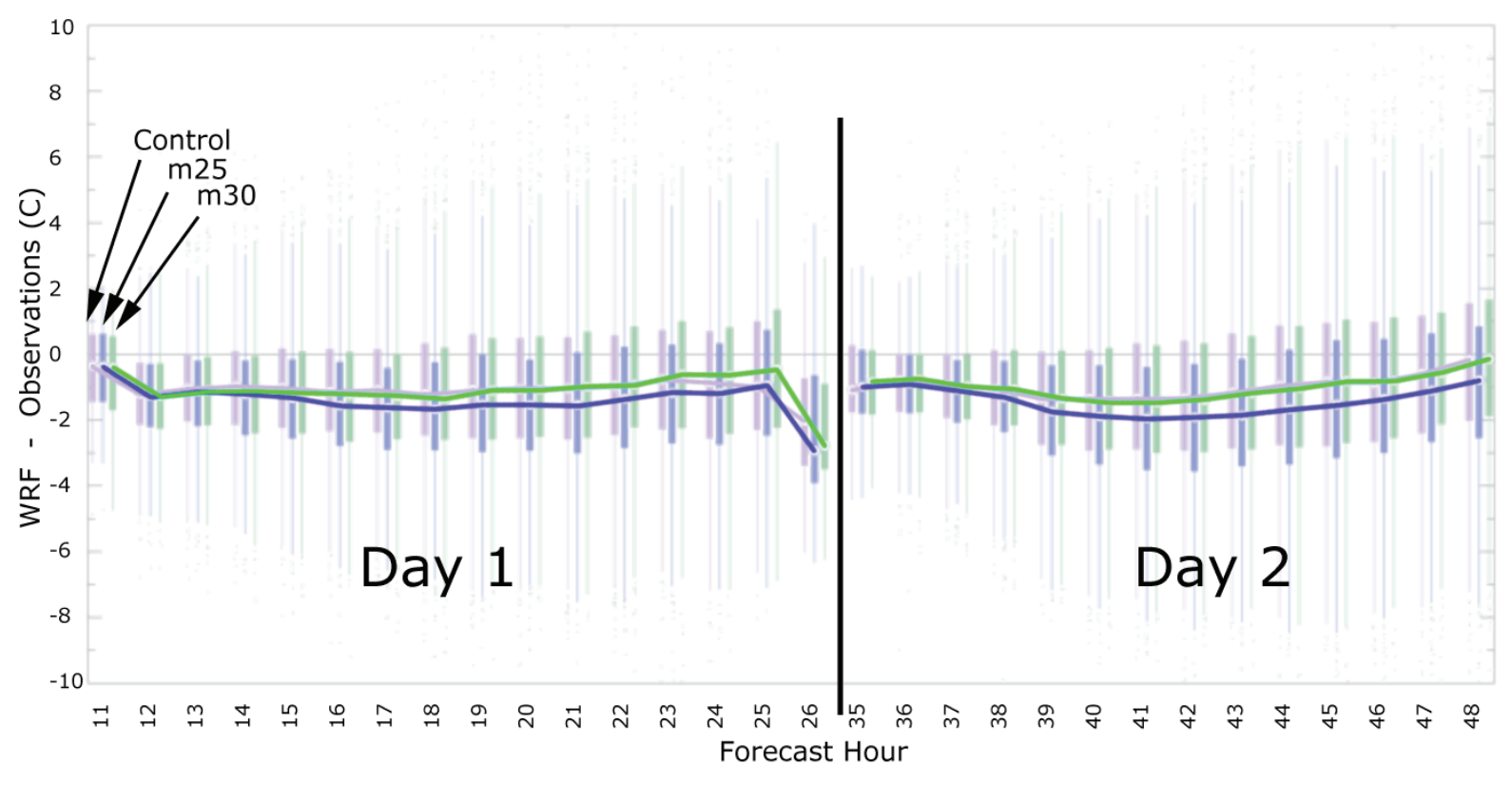

Figure12 Forecast Hour

\author{
recast Hour
}



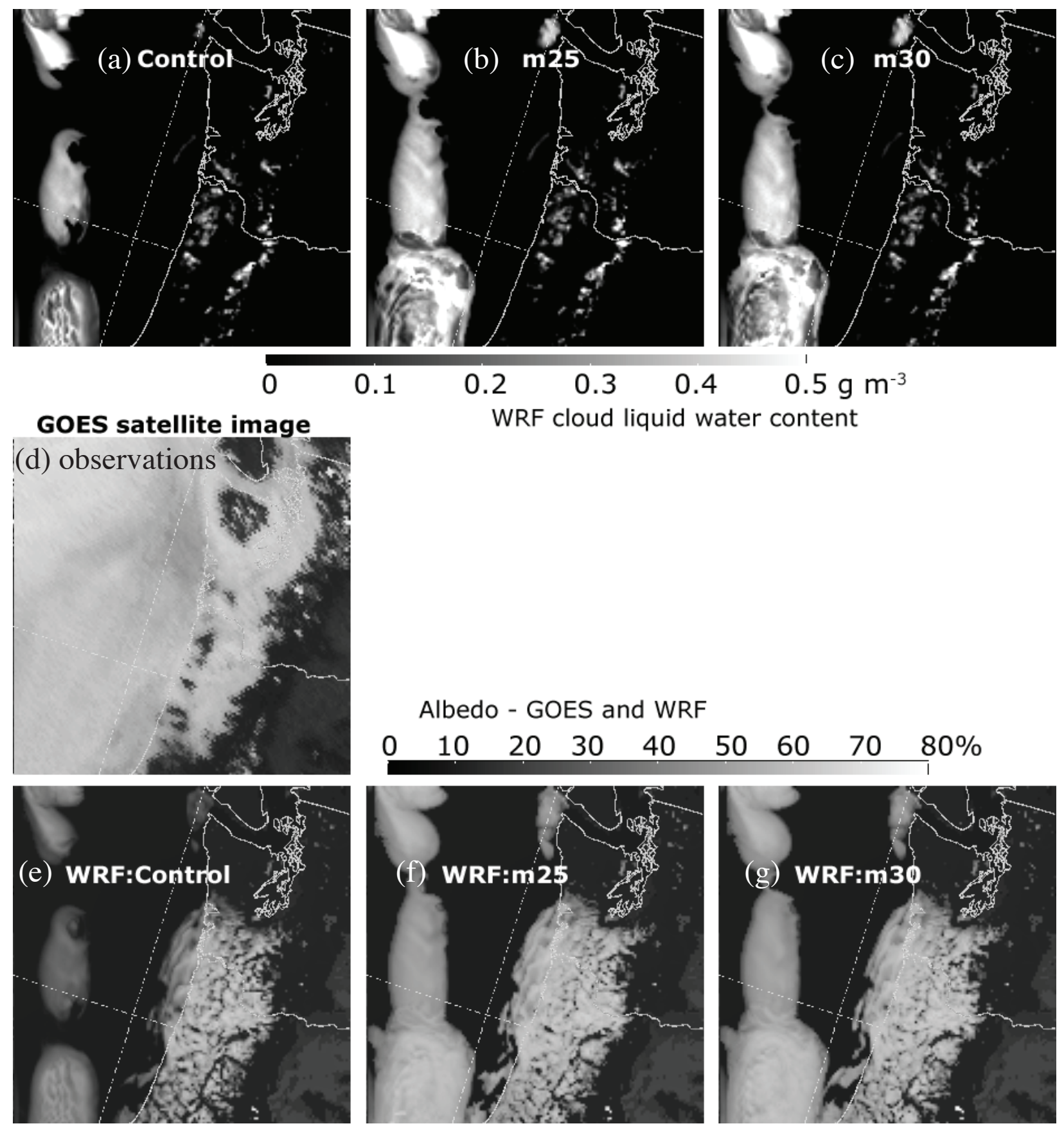

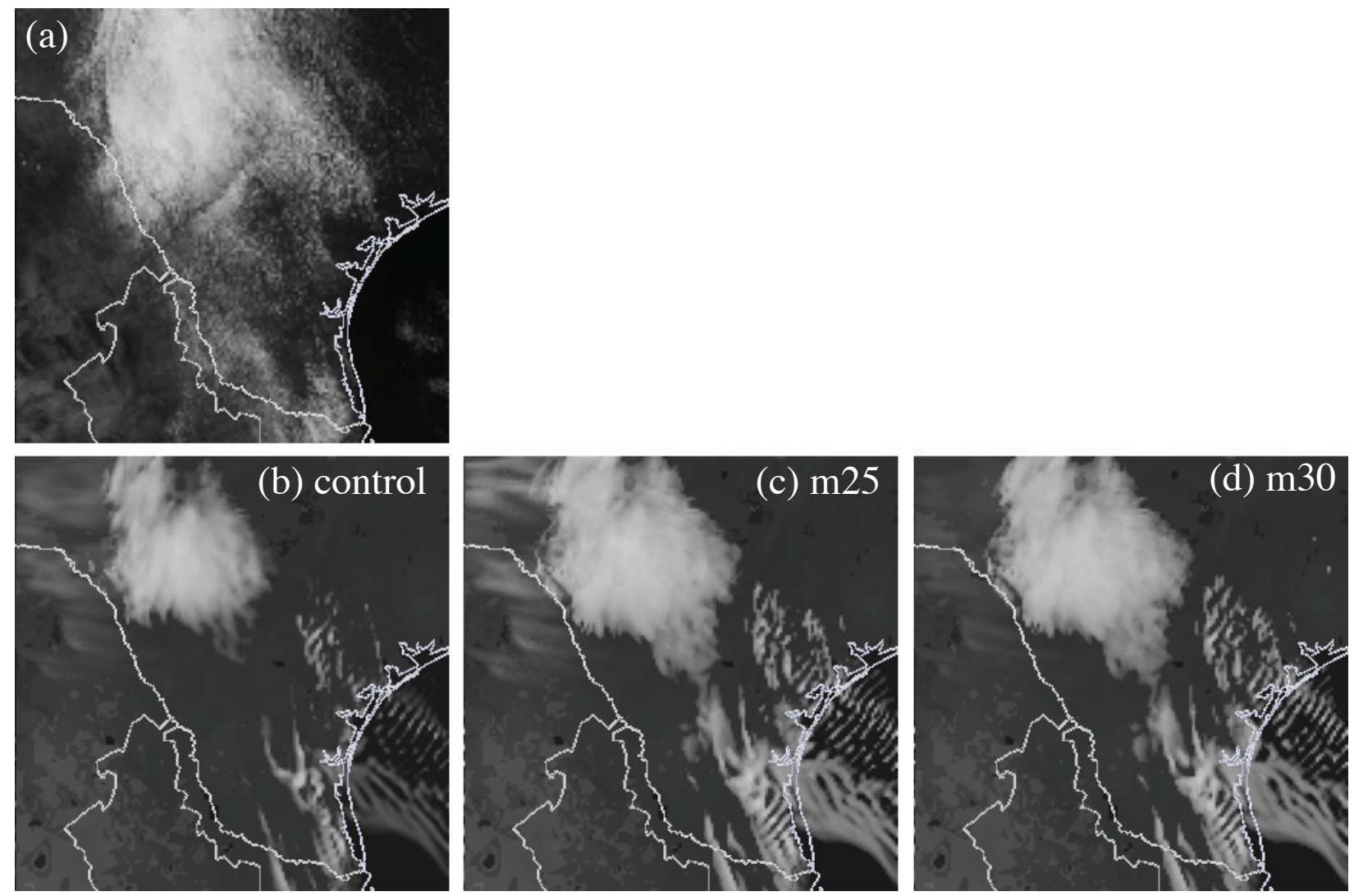
Fig. 1: GOES-13 visible (a) and infrared (b) satellite images at 17:45 UTC 01 Feb 2011 and sample WRF-model forecasts of shortwave radiation reaching the ground using the GFDL radiation scheme (c) and RRTMG scheme (d). In the version of GFDL radiation implemented into WRF the snow variable was ignored whereas RRTMG considers this species when computing radiation.

Fig. 2: The WRF model domain for 2013 OU-CAPS Spring Experimental Forecast with $1200 \times 768$ grid points spaced $4 \mathrm{~km}$ apart and 51 vertical levels. The dashed rectangle represents the outer 50 ring of points eliminated from analysis found in the Results subsection.

Fig. 3: The existing relationship between model temperature and assumed radiative effective radius of ice species in the WRF v3.4.1 code.

Fig. 4: A sample snow size distribution assumed in the Thompson et al. (2008) scheme and its associated radiative effective size assuming only the first term on R.H.S. of Eqn. (3), gray shading, as well as the full distribution and an example exponential distribution assumption.

Fig. 5: (a) GOES-13 channel 4 infrared (IR) satellite image valid 1745 UTC 08 May 2013 with numbered cloudy regions mentioned in the text, WRF synthetic IR satellite image from the (b) Control experiment, (c) m30 experiment, and (d) m25 experiment.

Fig. 6: Relative frequency of observed and WRF control member of specific $5^{\circ} \mathrm{C}$ intervals of infrared brightness temperature from all pixels (a) and from cloudy-only (b). Note the abundance of model points between 10 and $25^{\circ} \mathrm{C}$ as compared to observations, but also the deficit of model points between 0 and $-25^{\circ} \mathrm{C}$.

Fig. 7: Fraction of cloudy points from GOES observations (red) as a function of forecast hour (during relatively high solar angle) as compared to the WRF control ensemble member (blue) from 34 days of simulations. For each simulated hour during 34 days, the fraction of grid boxes containing clouds in the observations and simulations was calculated to create the boxplot. WRF consistently shows lower cloud fraction than observations. The fraction of the domain covered in clouds in both the observations and WRF is labeled "overlap" (green).

Fig. 8: Relative frequency of USCRN and Ameriflux observations of incoming surface solar radiation in bins of $100 \mathrm{~W}$ m-2 versus WRF control member regardless of whether the observing location has clouds or not (solid bars). The hatched bars represent observing locations diagnosed as having clouds overhead.

Fig. 9: Same as Fig. 8 except only at diagnosed cloudy points from the two days (May 08 and May 18) with all three WRF ensemble members.

Fig. 10: Differences in near-surface temperature $\left({ }^{\circ} \mathrm{C}\right)$ between WRF control member and (a) observations valid at 18:00 UTC 08 May 2013 (same time as Fig. 3). Differences in near-surface temperature $\left({ }^{\circ} \mathrm{C}\right.$ ) between control and $\mathrm{m} 25$ (b) and control and $\mathrm{m} 30$ (c).

Fig. 11: Box plot of (a) observed (METAR) and WRF forecast, near-surface temperature for all hours, 6 to 48 , from two days with all three WRF ensemble members. To distinguish WRF ensemble members, the lower panel (b) has the model minus observations distributions showing the generally lower temperatures in m 25 compared to the other members.

Fig. 12: The daytime evolution of near-surface temperature bias between the three WRF model ensemble members and METAR observations. The results of Control and $\mathrm{m} 25$ are nearly indistinguishable whereas m 25 clearly drifts to a larger negative bias as each forecast day progresses.

Fig. 13: Top row: cloud water content from control (a), m25 (b), and m30 (c) experiments at approximately $700 \mathrm{~m}$ MSL. Observed GOES-13 visible satellite image (d), and WRF synthetic satellite visible albedo from control (e), $\mathrm{m} 25(\mathrm{f})$, and $\mathrm{m} 30 \mathrm{~g}$ ) experiments. Note the minor improvement in increased cloud cover shown in m25 and m30.

Fig. 14: (a) GOES-13 visible satellite image, and WRF synthetic satellite visible albedo from control (b), m25 (c), and m30 (d) experiments. 